\section{8}

19

0

\title{
Ab initio modelling of an essential mammalian protein: Transcription Termination Factor 1 (TTF1)
}

Kumud Tiwari ${ }^{\mathrm{a} 1}$, Aditi Gangopadhyay ${ }^{\mathrm{b} 1}$, Gajender Singh ${ }^{\mathrm{a}}$, Samarendra Kumar Singh ${ }^{\mathrm{a}^{*}}$

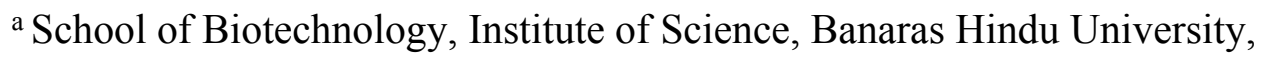

Varanasi, Uttar Pradesh 221005, India

${ }^{b}$ Department of Chemical Technology, University of Calcutta, Kolkata, West

Bengal 700009, India

${ }^{1}$ These authors contributed equally

${ }^{*}$ Corresponding author: Samarendra Kumar Singh

Cell Cycle and Cancer Laboratory, School of Biotechnology, Institute of Science, Banaras Hindu University, Varanasi, Uttar Pradesh 221005, India.

Phone: +91-8009561887, +91-8707400665

E-mail: samarendra.singh@bhu.ac.in; biotech3@rediffmail.com 


\section{Abstract}

23 Transcription Termination Factor $1(\mathrm{TTF} 1)$ is an essential mammalian protein that regulates

24 cellular transcription, replication fork arrest, DNA damage repair, chromatin remodelling etc.

25 TTF1 interacts with numerous cellular proteins to regulate various cellular phenomena, and

26 plays a crucial role in maintaining normal cellular physiology, dysregulation of which has

27 been reported towards cancerous transformation of the cells. However, despite its key role in

28 cellular physiology, the complete structure of human TTF1 has not been elucidated to date,

29 either experimentally or computationally. Hence, understanding the structure of human TTF1

30 becomes highly important for studying its functions and interactions with other cellular

31 factors. Therefore, the aim of this study was to construct the complete structure of human

32 TTF1 protein, using molecular modelling approaches. Owing to the lack of suitable

33 homologues in the PDB, the complete structure of human TTF1 was constructed using $a b$

34 initio modelling. The structural stability was determined using molecular dynamics (MD)

35 simulations in explicit solvent, and trajectory analyses. The representative structure of human

36 TTF1 was obtained by trajectory clustering, and the central residues were determined by

37 centrality analyses of the residue interaction network of TTF1. Two residue clusters, in the

38 oligomerisation domain and C-terminal domain, were determined to be central to the

39 structural stability of human TTF1. To the best of our knowledge, this study is the first to

40 report the complete structure of human TTF1, and the results obtained herein will provide

41 structural insights for future research in cancer biology and related studies.

42 Keywords: Transcription termination, DNA binding, ab initio modelling, molecular

43 dynamics simulation, network analysis, residue interaction network 


\section{Author Summary}

45 The transcription termination factor 1 (TTF1) is an essential multifunctional mammalian

46 protein which plays important role in regulating important cellular process like transcription,

47 replication, DNA damage repair, chromatin remodelling etc. and its dysregulation leads to

48 various cancers. Despite its being such an important factor, the complete structure of human

49 TTF1 has not been determined to date, either using experimental techniques or

50 computationally. Therefore, the aim of this study was to construct the complete structure of

51 human TTF1 using computational modelling. In this study the complete structure of human

52 TTF1 was constructed by ab initio modelling using iTasser. The stability of this model was

53 determined by 200 ns molecular dynamics (MD) simulations. The representative

54 conformation of human TTF1 was further determined by clustering the simulation trajectory

55 and the residues that are central to the stability of this structure were identified. The results

56 demonstrate the presence of two residue clusters in human TTF1, one in the oligomerisation

57 domain and other in the C-terminal domain, which were found to be crucial for the structural

58 stability of this protein. Hence, the results of this study will aid future studies in this field

59 towards engineering this important protein for further biochemistry and cell biology research.

60

61 Ribosomes are essential cellular organelles that partake in protein synthesis in both

62 prokaryotes and eukaryotes. Ribosomes are comprised of ribosomal proteins and ribosomal

63 RNA (rRNA), which is encoded by ribosomal DNA (rDNA), and serves as the catalytic

64 subunit of the protein translation machinery. Eukaryotic rDNA is distributed in clusters of

$65 \sim 300-400$ copies at both ends of the respective chromosomes (acrocentric chromosomes: 13, 
$6614,15,21$, and 22). These tandem repeats of rDNA copies create dense chromosomal regions

67 called Nucleolar Organizer Regions (NORs) which consists of a non-transcribed spacer

68 region flanked by pre-RNA coding regions. Of the total RNA that is transcribed, $80 \%$

69 consists of rRNAs [1,2]. Both the initiation and termination of rDNA transcription is

70 mediated by a transcriptional regulator called Transcription Termination Factor 1 (TTF1),

71 which is an essential protein in mammalian cells. The gene encoding TTF1 is located on

$729 q 34.13$, in the long arm of chromosome 9. Transcription Termination Factor 1 protein

73 (TTF1p) binds to DNA elements known as Sal box, located upstream and downstream of the

74 rDNA gene repeats. In mammalian cells, the Sal box element consists of a SalI restriction

75 site within the 11 bp sequence, GGGTCGACCAG [3]. Following its discovery as a

76 transcription regulator, subsequent studies demonstrated that TTF1 is involved in polar

77 replication fork arrest and also acts as a chromatin remodelling factor [4,5]. Current findings

78 demonstrate that TTF1p interacts with various DNA damage sensing proteins, including

79 Cockayne Syndrome B (CSB) [6], Mouse Double Minute 2 (MDM2) [7] and tumor

80 suppressor Alternative Reading Frame (ARF) [8] protein, but the mechanism and exact roles

81 of TTF1p remains to be identified to date. The overexpression of TTF1 has been corelated in

82 various tumours, which indicates that owing to tumor hyperproliferation, TTF1 is required

83 in higher quantities to meet the higher rate of ribosome biogenesis in tumor cells [9-11]. The

84 TTF1 protein has several other unidentified roles, as it appears to interact with various other

85 factors necessary for regulating a wide variety of physiological phenomena in cells. TTF1 is

86 truly a multifunctional protein, and hence, it becomes important to characterise the numerous

87 unidentified roles of this protein in cellular physiology both in healthy and cancerous cells. 
TTF1p has distinct functional domains, including an N-terminal regulatory domain

89

90

91

92

(NRD), which also is responsible for the oligomerisation of TTF1 [12]. It has been shown that due to its oligomerisation property, TTF1p can loop the ends of rDNA together, thereby placing the promoter and terminator regions in proximity to efficiently recycle the transcription machinery, and this model is known as the "ribomotor" model [13]. Furthermore, TTF1 has a functional central domain and a C-terminal domain, which is essential for the activation and termination of Pol I-mediated transcription on a nucleosomal rDNA template [14]. The central domain has the highly conserved DNA binding myb/SANTlike domain which has strong homology with the DNA binding domain of Reb1 protein of Schizosaccharomyces pombe, and proto-oncoprotein c-Myb $[15,16]$.

The only crystal structure of its yeast homolog protein, RNA Polymerase I enhancer binding protein (Reb1p) [17], bound to DNA, was solved to atomic resolution by our group [15]. The structure clearly shows an N-terminal regulatory domain which is also known as the dimerization domain, a central DNA-binding domain, and the C-terminal transcriptional terminator domain. Using various mutants, it was demonstrated that the mere binding of DNA to Reb1p is not sufficient for terminating transcription. Further it was shown that the interaction of Reb1p with Replication Protein A (RPA), via the C-terminal domain of Reb1p, is an essential requirement for effective transcriptional termination. The interaction with RPA induces an allosteric change which is necessary for stopping the movement of RNA polymerase I. Also, the domain of Reblp which binds to DNA was identified to atomic resolution and the residues involved in protein-DNA contacts were identified. This region consists of two myb-associated domains (mybAD1 and mybAD2) and two Myb repeats 
110 (mybR1 and mybR2). The helices involved in this region make contact with DNA at various 111 residues [17].

TTF1 is an essential cellular protein owing to its numerous roles in several vital

113 cellular functions, which are necessary for maintaining healthy cellular physiology.

114 Understanding the structure of TTF1 would provide insights into the mechanistic aspect of 115 its function. To date, there are no experimentally-determined structures or in silico models

116 of TTF1. Our lab is involved in purifying and physically solving the structure of this protein.

117 So far, crystallization trials have proved to be unsuccessful, and we are therefore attempting

118 cryo-EM studies as well. Alternatively, computational modelling studies on this essential

119 protein will provide a better understanding so that we can engineer the protein for future 120 studies.

In the absence of experimentally-derived structures, homology modelling serves as a

122 reliable method for the construction of protein structures. However, the reliability of the

123 protein model depends on various factors, including the sequence identity between the

124 template and target proteins. When the template-target identity falls below $30 \%$, known as

125 the twilight zone, the protein structure needs to be constructed by threading or ab initio 126 methods [18]. This is due to the fact that below the twilight zone, the evolutionary relatedness

127 between the template and target is doubtful, and the confidence of the prediction is low [19].

128 The worldwide experiment for protein structure prediction, Critical Assessment of protein

129 Structure Prediction (CASP), ranked the iTasser (iterative threading assembly refinement)

130 server as the best tool for $a b$ initio protein modelling. In the latest CASP14 experiment 131 conducted in 2020, the iTasser server (Zhang server) ranked the best among 47 groups 
132 [20,21]. The iTasser server also ranked best in the previous CASP7, CASP8, CASP9,

133 CASP10, CASP11, CASP12, and CASP13 experiments [22]. In the CASP9 experiments in

1342010 , the iTasser server was predicted to the best tool for protein function prediction [21]. In

135 this study, the structure of the TTF1 protein was constructed by molecular modelling, using

136 the iTasser server. The predicted models were validated and the structure was subjected to

137 molecular dynamics (MD) simulations for $200 \mathrm{~ns}$ for studying the structural stability of

138 TTF1, and determining the most stable conformation of the protein. Our study aimed to

139 predict the structure of TTF1, which is an essential protein, using computational modelling.

140 The results of our study will prove to be important for understanding the structural,

141 functional, and therapeutic role of this essential protein.

142 2. Results

$143 \quad 2.1$ Sequence-based analyses

144 The results of sequence-based analysis with ProtParam showed that TTF1 is an unstable

145 hydrophilic protein, as revealed by an instability index of 51.13 and grand average of

146 hydrophobicity (GRAVY) of -0.939 . This was corroborated by the results of disorder

147 prediction, which showed that more than $50 \%$ of the residues of TTF1 are disordered (Fig

148 1). The results of disorder prediction further revealed that residues 1-3, 689-696, 700-701,

149 709, and 903-905 were disordered and had protein binding properties (S1 Fig). The

150 physicochemical properties predicted by ProtParam and anticipation of disulphide bond (S-

151 S) pattern by CYS REC tool are enlisted in Table 1.

152 Table 1: Physicochemical properties of TTF1, as determined with ProtParam. 


\begin{tabular}{|l|l|}
\hline Physicochemical Properties & Values \\
\hline Number of residues & 905 \\
\hline Molecular formula & $\mathrm{C}_{4512} \mathrm{H}_{7282} \mathrm{~N}_{1302} \mathrm{O}_{1399} \mathrm{~S}_{28}$ \\
\hline Molecular weight & $103 \mathrm{kDa}$ \\
\hline Theoretical pI & 9.41 \\
\hline Instability index & 51.13 \\
\hline Aliphatic index & 65.09 \\
\hline Total number of negatively charged residues (D+E) & 135 \\
\hline Total number of positively charged residues (R+K) & 171 \\
\hline Extinction coefficient & 96760 \\
\hline Grand average of hydrophobicity (GRAVY) & -0.939 \\
\hline Estimated half-life (mammalian reticulocyte, in vitro) & 30 hours \\
\hline S-S Bond (predicted) & $22-737,73-887,445-892$ \\
\hline
\end{tabular}

154 Fig 1: Graphical representation of the disordered regions of the human TTF1 protein.

155 Residues with disorder score $\geq 0.5$ (represented by the horizontal red line) were considered 156 to be disordered.

\section{$157 \quad 2.2$ Ab inito modelling and structural validation of TTF1}

158 The results of template search using BLASTp against the PDB revealed that the highest 159 target-template coverage was $4 \%$, which was well below the twilight zone for homology 160 modelling [23]. Therefore, the structure of human TTF1 could not be modelled using the 
161 template-based methods in comparative modelling. The complete structure of human TTF1p

162 was therefore modelled using ab initio methods, using the iTasser server. The confidence of

163 the models predicted by iTasser are indicated by the C-score, which is a confidence score 164 that provides a measure of the quality of the models generated by iTasser. The C-scores range

165 between -5 and 2, with higher values indicating predictions of higher confidence, while lower

166 values of C-score indicate predictions of lower confidence [20]. In this study, the model with

167 the highest C-score of -0.60 was selected for subsequent analyses. This model was further

168 minimised using Yasara, and the energy minimised structure was validated using ProSA

$169[24,25]$. The results of ProSA validation revealed that the structure of TTF1 was comparable

170 to structures of similar size in the PDB, which had been determined using X-ray

171 crystallography (Fig 2A). Analysis of the Ramachandran plot with Procheck revealed that

172 only $1.0 \%$ of the residues were in the disallowed regions of the plot, while $82.9 \%$ and $14.1 \%$

173 of the residues were in the most favoured and additional allowed regions, respectively (Fig $1742 B)$.

175 Fig 2: Structural validation of the energy minimised model of TTF1 using A) ProSA and B)

176 Ramachandran plot analysis with Procheck.

$177 \quad$ 2.3. Functional validation of TTF1

178 The results of analysis with TM-align revealed that the model of TTF1 generated by iTasser

179 (Fig 3) was structurally most similar to cas13b (PDB ID: 6AAY), which is an RNA-binding 180 protein from Bergeyella zoohelcum with RNase activity [26]. The human TTF1 protein is a 181 DNA-binding protein that plays an important role in transcriptional termination. The TM182 score of the alignment was 0.960 , indicating correct topology, and the RMSD between the 
183 generated model of TTF1 and cas13b was $2.29 \AA$, indicating high structural similarity

184 between the two proteins. The structural similarity between TTF 1 and cas $13 \mathrm{~b}$ indicated that

185 the model of TTF1 obtained herein, possesses potential nucleic acid binding properties,

186 similar to cas $13 \mathrm{~b}$.

187 Fig 3: The structure of TTF1 constructed by ab initio modelling is depicted in light blue 188 ribbon representation, and the structure obtained after minimisation with Yasara is depicted 189 in dark blue ribbon representation.

190 The results of ligand binding analyses with COFACTOR and COACH revealed that residues

191 620-626 of the TTF1 model have potential binding property to the ligand 192 phosphoaminophosphonic acid-adenylate ester (ANP). ANP is a non-hydrolysable analogue 193 of ATP, and comprises triphosphate, adenine, and ribose sugar moieties, similar to the 194 composition of DNA. This indicated that the model of TTF1 predicted using iTasser has 195 potential nucleic acid binding properties, and logically relates to the DNA-binding properties 196 of TTF1 reported in literature and also been validated in our lab using the purified TTF1 197 protein [3]. The ligand binding properties of the model of TTF1 were predicted to be most 198 similar to those of the recombinase A protein of Escherichia coli (PDB ID: 3CMV), which 199 possesses single-stranded DNA binding properties. These results indicated that the model of 200 TTF1 possesses potential DNA binding properties, in agreement with the reports in existing 201 literature and our experimental data (not shown here). The results of CD analyses revealed 202 that residues 621-677 of TTF1 comprises the Myb-like DNA binding domain of TTF1 (pfam 203 accession number: 13921) (S 2 Fig). The results of sequence-based CD analysis of TTF1 204 corroborated with the results of structure-based ligand binding site prediction by 
205 COFACTOR and $\mathrm{COACH}$, further validating the DNA-binding potential, and thus the

206 functional potential of the model of TTF1 constructed using iTasser. Furthermore, the

207 residues with ANP-binding properties mapped to the DNA-binding domain of TTF1, 208 implying the potential nucleotide binding properties of the structure of TTF1 generated by

209 iTasser.

210 The results of consensus-based GO prediction revealed that the molecular function of the

211 TTF1 protein model was associated with GO terms GO:0035639 (purine ribonucleoside 212 triphosphate binding), GO:0032559 (adenyl ribonucleotide binding), and GO:0043167 (ion

213 binding), with GO scores of $0.40,0.40$, and 0.39 , respectively. These results further 214 confirmed the nucleotide binding properties of the structure of TTF1 obtained with iTasser.

215 The results of functional validation thus implied that the TTF1 model obtained using ab initio

216 modelling has potential nucleic acid-binding properties, and agrees with the data reported in

217 literature and observed in our lab.

$218 \quad$ 2.4. Trajectory analyses

219 The structural model of TTF1 thus obtained by ab initio modelling was subjected to $200 \mathrm{~ns}$

220 MD simulations for investigating the structural stability and determining any possible

221 conformational changes in TTF1. Trajectory visualisation revealed that the protein stabilised

222 after $20 \mathrm{~ns}$ and remained stable thereafter. This was further observed in the values of root

223 mean square deviation RMSD, which became steady after 20 ns (Fig 4). As depicted in the

224 Fig 4A, the values of RMSD became increasingly steady after $100 \mathrm{~ns}$, and remained steady 225 thereafter, with fluctuations in the RMSD values being in the range of 1-1.5 $\AA$. This indicated 226 that the system had reached equilibrium after $100 \mathrm{~ns}$ and remained stable thereafter. This was 
227 further corroborated by the values of RoG (Fig 4B), which remained steady after 100 ns. The

228 RoG is an indicator of structural compactness, and fluctuations in the values of RoG indicate

229 protein unfolding. The fact that the values of RoG became steady after $100 \mathrm{~ns}$ indicated that

230 the structure of TTF1 was stable and compact during the production run. Analysis of the

231 values of RMSF revealed that some residues had higher flexibility, as indicated by the RMSF

232 values, which were higher than $1.5 \AA$. The higher flexibility of these residues could be

233 attributed to the fact that these residues mapped to the disordered regions predicted using

234 DisoPred (Fig 4C).

235 Fig 4: Graphical representation of the values of A) RMSD and B) RoG of the protein

236 backbone throughout the trajectory. C) Comparison of the average RMSF values and disorder

237 scores of TTF1. The oligomerisation domain (residues 1-320), Myb domain 1 (residues 612-

238 660), Myb domain 2 (residues 661-745), and chromatin remodelling region (residues 323-

239445 ) are indicated by blue, yellow, red, and green rectangles, respectively.

\subsection{Representative structure of TTF1}

241 The trajectory was clustered using Chimera v1.14, and the representative frame of the most

242 populated cluster was selected as the representative conformation of TTF1 (Fig 5A, refer to

243 the supplementary for coordinate file). The oligomerisation domain (residues 1-320), Myb

244 domain 1 (residues 612-660), Myb domain 2 (residues 661-745), and chromatin remodelling

245 region (residues 323-445,) [5,12,16] were mapped to the complete structure of TTF1 obtained

246 herein (Fig 5B). 
247 Fig 5: A) Ribbon and B) Surface representation of the representative structure of TTF1

248 obtained by trajectory clustering. The oligomerisation domain, Myb domain 1, Myb domain

249 2, and chromatin remodelling region are represented in blue, yellow, red, and green, 250 respectively.

\section{$251 \quad 2.6$. Centrality analyses}

252 The RINs of the representative structure of TTF1 was determined using Cytoscape v3.8.2

253 (Fig 6), and the central residues were identified using the RINspector plugin, based on the

254 RCA Z-scores. In the RIN, the nodes indicate the residues, while the edges represent the

255 intra-residue interactions. Residues with RCA Z-scores $\geq 2$ were considered to be central to 256 the structural stability of the protein. As depicted in Fig 6, the residues with Z-scores $\geq 2$ are

257 coloured in yellow, and those with Z-scores $\geq 2$ are represented in red. The bigger nodes

258 indicate residues with higher values of Z-scores. The RIN revealed two interaction clusters,

259 with one cluster being located in the oligomerisation domain of TTF1, and the other being

260 located towards the C-terminal region of the protein (Fig 6A and 6B). The Z-scores of the

261 residues in the interaction cluster in the oligomerisation domain were higher than those of

262 the residues in the C-terminal domain, indicating that the interaction cluster in the

263 oligomerisation domain plays a more crucial role in the stability of the human TTF1 protein

264 than that of the interaction cluster in the C-terminal domain. The Z-scores of the central

265 residues determined by centrality analysis are enlisted in Table 2. 
267 Fig 6: The central residues of TTF1 identified by RIN and centrality analyses in the A) 3-

268 dimensional structure of TTF1. B) The central residues in the RIN of TTF1 in 2D

269 representation. The nodes and edges represent the residues and inter-residue interactions,

270 respectively. The size of the nodes corresponds to the value of the RCA Z-score, with bigger

271 nodes corresponding to residues with higher values of Z-scores. The residues with RCA Z-

272 score $\geq 2$ and $\geq 4$ are indicated in yellow and red, respectively.

273 Table 2: Central residues of TTF1, determined by centrality analysis

\begin{tabular}{|l|l|l|l|}
\hline Central residue & Corresponding domain & RCA Z-score & Secondary structure \\
\hline K68 & Oligomerisation & 7.246 & Loop \\
\hline E196 & Oligomerisation & 7.2 & Helix \\
\hline R71 & Oligomerisation & 7.161 & Loop \\
\hline E195 & Oligomerisation & 7.111 & Loop \\
\hline Q30 & Oligomerisation & 7.097 & Helix \\
\hline HIE34 & Oligomerisation & 6.991 & Helix \\
\hline W198 & Oligomerisation & 6.813 & Helix \\
\hline R38 & Oligomerisation & 6.682 & Helix \\
\hline G202 & Oligomerisation & 6.555 & Loop \\
\hline E35 & Oligomerisation & 6.453 & Helix \\
\hline K17 & Oligomerisation & 6.366 & Helix \\
\hline E206 & Oligomerisation & 5.788 & Helix \\
\hline K31 & Oligomerisation & Helix \\
\hline
\end{tabular}




\begin{tabular}{|l|l|l|l|}
\hline S226 & Oligomerisation & 4.417 & Loop \\
\hline E27 & Oligomerisation & 4.309 & Helix \\
\hline T186 & Oligomerisation & 4.204 & Loop \\
\hline N228 & Oligomerisation & 3.947 & Loop \\
\hline R229 & Oligomerisation & 3.614 & Loop \\
\hline S23 & Oligomerisation & 3.159 & Helix \\
\hline I660 & myb/SANT-like 1 & 2.83 & Helix \\
\hline R664 & myb/SANT-like 2 & 2.825 & Loop \\
\hline K434 & Chromatin remodelling & 2.782 & Helix \\
\hline F657 & myb/SANT-like 1 & 2.778 & Helix \\
\hline R164 & Oligomerisation & 2.769 & Loop \\
\hline E165 & Oligomerisation & 2.693 & Loop \\
\hline S895 & - & 2.469 & Helix \\
\hline N893 & - & 2.593 & Helix \\
\hline E882 & - & 2.661 & Loop \\
\hline T896 & Oligomerisation & 2.608 & Loop \\
\hline S161 & Oligomerisation & Helix \\
\hline Q172 & - & 2.596 & Loop \\
\hline E191 & & 2.499 & Loop \\
\hline E431 & & & \\
\hline G899 & & & \\
\hline & & & \\
\hline
\end{tabular}




\begin{tabular}{|l|l|l|l|}
\hline S435 & Chromatin remodelling & 2.388 & Helix \\
\hline R902 & - & 2.326 & Loop \\
\hline R182 & Oligomerisation & 2.302 & Helix \\
\hline D471 & - & 2.069 & Helix \\
\hline
\end{tabular}

\subsection{Intra-residue hydrogen bonds}

276 Hydrogen bonds with occupancy $\geq 75 \%$ and $\geq 85 \%$ throughout the 200 ns trajectory and in

277 the last $50 \mathrm{~ns}$, respectively, were considered to be important for the structural stability of the

278 protein. The frequency of the hydrogen bonds throughout the trajectory and in the last $50 \mathrm{~ns}$

279 was determined using VMD. The occupancy of the intra-residue hydrogen bonds formed by

280 the central residues is provided in S 1 Table, and the occupancy of all the intra-residue

281 hydrogen bonds with occupancy $\geq 75 \%$ and $\geq 85 \%$ throughout the 200 ns trajectory and in

282 the last $50 \mathrm{~ns}$, respectively, are provided in the S 1 Table. The results of interaction analyses

283 revealed that residues K17, E27, Q30, E35, R164, W198, and N228 of the oligomerisation

284 domain, K434 of the chromatin remodelling region, and F657 of the myb/SANT-like-1

285 domain were most crucial to the structural stability of the protein, as indicated by the number

286 of intra-residue hydrogen bonds and the occupancy of the hydrogen bonds throughout the

287 trajectory.

\section{3. Discussion}

289 TTF1 is a crucial multifunctional nucleolar protein that regulates both transcription initiation

290 as well as transcriptional termination of ribosomal genes by binding to specific motif 
291 sequence and-also arrests of the replication fork in polar fashion [2]. In addition, TTF1

292 regulates the transcription of genes transcribed by RNA polymerase I. Using truncated human

293 and murine TTF1 proteins, Evers and Grummt first reported species-specific sequence 294 differences in the DNA-binding region of mammalian TTF1 [3]. Despite its major regulatory 295 role in mammalian transcription, replication and chromatin remodelling, the complete 296 structure of human TTF1 remains to be elucidated to date. A partial structure of human TTF1 297 has been predicted by AlphaFold v2.0, which uses artificial intelligence for predicting the 3298 dimensional structure of proteins. However, the structure predicted by AlphaFold is partial 299 (residues 491-866), and the remaining residues are largely unfolded, and the confidence of 300 prediction of these unfolded regions is very low [27]. As all the residues of a protein are 301 important for its complete regulation and function, it is necessary to consider that protein in 302 its entirety in structural analyses. In this study, we therefore attempted to construct the 303 complete structure of the human TTF1 protein using ab initio modelling and MD simulations, 304 and also identified the residues that are central to the structural stability of human TTF1 by 305 network analyses. To the best of our knowledge, this study is the first to report the complete 306 structure of the human TTF1 protein (refer supplementary for coordinate file).

307 Owing to the lack of suitable structural homologues in the PDB with sequence coverage 308 above the twilight zone, the structure of TTF1 was modelled using ab initio methods. The 309 model of TTF1 thus obtained was subjected to functional validation and GO analysis for 310 establishing the functional relevance. MD simulations are frequently used for obtaining 311 atom-level insights into the structural dynamics and behaviour of biomolecular system. The 312 stability of the model was subsequently evaluated by MD simulation for $200 \mathrm{~ns}$, using an 
313 explicit TIP4P solvent, and the trajectory was analysed for investigating structural stability

314 and hydrogen bond frequency. The representative conformation of the human TTF1 protein

315 was obtained by trajectory clustering, and the residues that play a central role in the structural

316 stability of TTF1 were identified by network analysis and determination of residue centrality.

317 The results of RIN analysis and computation of centrality measures revealed two interaction

318 clusters in the structure of human TTF1, with one in the oligomerisation domain of TTF1

319 and the other in the C-terminal domain. The data further indicated that the residue cluster in

320 the oligomerisation domain plays a more significant role in the stability of TTF1, compared

321 to that in the C-terminal domain. The N-terminal oligomerization domain has been shown to

322 play important regulatory function [2] while the C-terminal domain is involved in

323 transcription termination [5]. In the absence of experimentally-derived structural data

324 pertaining to the human TTF1 protein, we believe that the results of our study provide

325 valuable structural information, including domain architecture, and their characteristics,

326 among others. Hence, our study could facilitate future studies aimed towards understanding

327 the mechanism underlying the function of the human TTF1, including its interaction with

328 other protein, and for engineering this protein with the purpose of solving its physical

329 structure, drug design and therapeutic applications etc.

\section{4. Conclusion}

331 Conclusively, this is very first study to report complete structure of the essential human TTF1

332 protein, using computational modelling, and identify the residues and its characteristics that

333 are central to the structural stability of the protein. 


\subsection{Sequence retrieval and sequence-based analyses}

336

338

The sequence of TTF1 was retrieved from UniProtKB (UniProtKB accession number: Q15361). The physicochemical properties of TTF1 were analyzed using ProtParam [28], and the disorder profile was analyzed using DisoPred version $3.1[29,30]$.

\subsection{Ab initio modelling of TTF1}

The structural homologues of human TTF1 in the PDB was searched using BLASTp and threading-based approaches, for identifying suitable templates for homology modelling.

Owing to the lack of suitable structural templates, the structure of human TTF1 was modelled using ab initio modelling, using the iTasser server [20]. In the iTasser algorithm, the final models are selected using the SPICKER program for clustering the generated structures. The structure of TTF1 generated by iTasser was initially minimised using the Yasara energy minimization server, with the Yasara force field [24]. The energy minimised structure was then validated using Ramachandran plot analysis and ProSA [31,32].

\subsection{Functional validation of TTF1 constructed by ab initio modelling}

The models generated by iTasser were functionally validated using the TM-align program for determining the structures in the PDB that are structurally, and thus functionally, similar to the models of TTF1p constructed by ab initio modelling. The TM-align program was used to identify structures in the PDB that are structurally similar to the model generated by iTasser. This program determines the similarity between proteins on the basis of the TMscore, a scoring function that provides a quantitative measure of topological similarity between proteins [33]. It provides a measure of structural similarity, with values $>0.5$ 
356 indicating models of correct topology [34]. The models were further validated using the

$357 \mathrm{COACH}$ and COFACTOR programs for predicting the ligand binding sites, based on the

358 similarity of the protein folds with functional templates [35,36]. The result of ligand binding

359 site prediction was mapped to the results of sequence-based conserved domain (CD) analyses

360 using the CD search tool of NCBI [37]. The molecular function of the modelled protein was

361 further validated by consensus-based gene ontology (GO) search.

\section{$362 \quad 5.4$ MD simulations}

363 The model of TTF1 obtained by ab initio modelling was subjected to MD simulations for

364200 ns using Flare v4, which is based on the OpenMM Toolkit, for studying the structural

365 stability and determining any possible conformational changes of TTF1p. The protein was

366 then prepared in Flare v4 at pH 7.4, and solvated in TIP4P solvent using a buffer of $10 \AA$

367 thickness. The system was subsequently neutralised by the addition of $28 \mathrm{Cl}^{-}$ions. The

368 system was then minimized until the energy tolerance reached $0.25 \mathrm{Kcal} / \mathrm{mol}$, and

369 subsequently equilibrated for 200 ps. It was then finally subjected to $200 \mathrm{~ns}$ MD simulations

370 at a temperature of $298 \mathrm{~K}$ and a pressure of 1 bar, using the XED force field and the NPT

371 ensemble. The timestep was set to 2 fs.

The values of root mean square deviation (RMSD), root mean square fluctuations

373 (RMSF), and radius of gyration (RoG) of the protein backbone throughout the trajectory was

374 analyzed using the vmdICE plugin in VMD v1.9.3 [38,39]. The occupancy of the inter-

375 residue hydrogen bonds throughout the $200 \mathrm{~ns}$ trajectory and in the last $50 \mathrm{~ns}$ was determined

376 using VMD v1.9.3. The portion of the trajectory following equilibration was clustered using 
377 Chimera v1.14, and the representative frame of the most populated cluster was selected as

378 the representative conformation of TTF1p [40].

$379 \quad 5.5$ Determination of residue interaction networks (RINs) and centrality analysis

380 The RINs of TTF1p were determined using the RINalyzer plugin in Cytoscape v3.8.2

$381[41,42]$. The network centrality measures were computed using the RINspector plugin in

382 Cytoscape v3.8.2, based on the residue centrality analysis (RCA) Z-score.

383 Conflicts of interest

384 The authors have no conflicts of interest to declare.

385 Acknowledgement

386 The authors are thankful to the Director Prof. A.K. Tripathi and Coordinator Prof. S.M.

387 Singh, School of Biotechnology, Institute of Science, Banaras Hindu University for 388 providing space and facilities to conduct the research. We thank Dr. V.K. Singh for providing

389 valuable suggestions during the study. We are thankful to Department of Biotechnology, 390 Govt. of India for funding Samarendra K Singh (SKS) and Kumud Tiwari (KT) with grant 391 and fellowship respectively. Author Aditi Gangopadhyay (AG) acknowledges the Council of 392 Scientific and Industrial Research (CSIR), New Delhi, for providing financial assistance. We 393 also thank CSIR for funding the fellowships of Gajender Singh (GS).

\section{Author contribution}

395 SKS was involved in the Conceptualization and designing; Supervision; Writing - critical 396 review \& editing of the manuscript. KT and AG involved in Data curation; Formal analyses; 
397 Investigation; Methodology; Project administration; Resources; Software; Validation;

398 Visualization; Writing - original draft; review \& editing of the manuscript. GS contributed

399 analyses tools and data; Visualization; Writing - original draft.

\section{$400 \quad$ Funding statement}

401 The research was funded by Department of Biotechnology (DBT), Govt. of India, RLS grant

402 (BT/RLF/Re-entry/43/2016) to SKS and JRF fellowship to KT. Council of Scientific and

403 Industrial Research (CSIR) also supported this research by funding AG (RA grant 404 number: 09/028(1088)2019-EMR-I) and GS (JRF) by awarding fellowships.

405

406

\section{References}

407 1. Zhou H, Wang Y, Lv Q, Zhang J, Wang Q, Gao F, et al. Overexpression of

408 ribosomal RNA in the development of human cervical cancer is associated with

$409 \quad$ rDNA promoter hypomethylation. PLoS One. 2016;11: e0163340.

410 doi:10.1371/journal.pone.0163340

411 2. Akamatsu Y, Kobayashi T. The Human RNA Polymerase I Transcription Terminator

412 Complex Acts as a Replication Fork Barrier That Coordinates the Progress of

413 Replication with rRNA Transcription Activity. Mol Cell Biol. 2015;35: 1871-1881.

414 doi:10.1128/mcb.01521-14

415 3. Evers R, Grummt I. Molecular coevolution of mammalian ribosomal gene terminator sequences and the transcription termination factor TTF-I. Proc Natl Acad Sci U S A. 
418 4. Pütter V, Grummt F. Transcription termination factor TTF-I exhibits contrahelicase 419 activity during DNA replication. EMBO Rep. 2002;3: 147-152. doi:10.1093/embo$420 \quad$ reports/kvf027

421 5. Längst G, Blank TA, Becker PB, Grummt I. RNA polymerase I transcription on 422 nucleosomal templates: The transcription termination factor TTF-I induces 423 chromatin remodeling and relieves transcriptional repression. EMBO J. 1997;16: $424 \quad 760-768$. doi:10.1093/emboj/16.4.760

425 6. Aamann MD, Muftuoglu M, Bohr VA, Stevnsner T. Multiple interaction partners for 426 Cockayne syndrome proteins: Implications for genome and transcriptome 427 maintenance. Mech Ageing Dev. 2013;134: 212-224. doi:10.1016/j.mad.2013.03.009

429 7. Lessard F, Stefanovsky V, Tremblay MG, Moss T. The cellular abundance of the 430 essential transcription termination factor TTF-I regulates ribosome biogenesis and is 431 determined by MDM2 ubiquitinylation. Nucleic Acids Res. 2012;40: 5357-5367. doi:10.1093/nar/gks198

433 8. Lessard F, Morin F, Ivanchuk S, Langlois F, Stefanovsky V, Rutka J, et al. The ARF 434 Tumor Suppressor Controls Ribosome Biogenesis by Regulating the RNA Polymerase I Transcription Factor TTF-I. Mol Cell. 2010;38: 539-550. doi:10.1016/j.molcel.2010.03.015

437 9. Stults DM, Killen MW, Williamson EP, Hourigan JS, Vargas HD, Arnold SM, et al. 438 Human rRNA gene clusters are recombinational hotspots in cancer. Cancer Res. 
2009;69: 9096-9104. doi:10.1158/0008-5472.CAN-09-2680

440 10. Komatsu H, Iguchi T, Ueda M, Nambara S, Saito T, Hirata H, et al. Clinical and

441 biological significance of transcription termination factor, RNA polymerase $\mathrm{i}$ in

442 human liver hepatocellular carcinoma. Oncol Rep. 2016;35: 2073-2080.

$443 \quad$ doi:10.3892/or.2016.4593

444 11. Ueda M, Iguchi T, Nambara S, Saito T, Komatsu H, Sakimura S, et al.

445 Overexpression of Transcription Termination Factor 1 is Associated with a Poor

446 Prognosis in Patients with Colorectal Cancer. Ann Surg Oncol. 2015;22: 1490-1498.

447 doi:10.1245/s10434-015-4652-7

448 12. Sander EE, Grummt I. Oligomerization of the transcription termination factor TTF-I:

449 Implications for the structural organization of ribosomal transcription units. Nucleic

$450 \quad$ Acids Res. 1997;25: 1142-1147. doi:10.1093/nar/25.6.1142

451 13. Németh A, Guibert S, Tiwari VK, Ohlsson R, Längst G. Epigenetic regulation of

452 TTF-I-mediated promoter-terminator interactions of rRNA genes. EMBO J.

$453 \quad 2008 ; 27:$ 1255-1265. doi:10.1038/emboj.2008.57

454 14. Boutin J, Lessard F, Tremblay MG, Moss T. The short N-terminal repeats of transcription termination factor 1 contain semi-redundant nucleolar localization signals and P19-ARF tumor suppressor binding sites. Yale J Biol Med. 2019;92: 385-396. Available: /pmc/articles/PMC6747939/

458 15. Jaiswal R, Choudhury M, Zaman S, Singh S, Santosh V, Bastia D, et al. Functional 459 architecture of the Reb1-Ter complex of Schizosaccharomyces pombe. Proc Natl 
461 16. Park SH, Yu KL, Jung YM, Lee SD, Kim MJ, You JC. Investigation of functional 462 roles of transcription termination factor-1 (TTF-I) in HIV-1 replication. BMB Rep. 2018;51: 338-343. doi:10.5483/BMBRep.2018.51.7.032 by Reb1 Protein-Mediated Action at a Distance. Cell. 2010;142: 868-878. doi:10.1016/j.cell.2010.08.013

18. Khor BY, Tye GJ, Lim TS, Choong YS. General overview on structure prediction of twilight-zone proteins. Theor Biol Med Model. 2015;12. doi:10.1186/s12976-0150014-1

19. Chung SY, Subbiah S. A structural explanation for the twilight zone of protein sequence homology. Structure. 1996;4: 1123-1127. doi:10.1016/S0969-

20. Roy A, Kucukural A, Zhang Y. I-TASSER: A unified platform for automated protein structure and function prediction. Nat Protoc. 2010;5: 725-738. 2126(96)00119-0 structure and function prediction. Nature Methods. Nat Methods; 2014. pp. 7-8. doi:10.1038/nmeth.3213 
Function and Bioinformatics. Proteins; 2019. pp. 1011-1020.

482 doi:10.1002/prot. 25823

23. Rost B. Twilight zone of protein sequence alignments. Protein Eng. 1999;12: 85-94. doi:10.1093/protein/12.2.85

485

486

487

488

489

490

491

492

493

494

495

496

497

498 499

500

501
24. Krieger E, Joo K, Lee J, Lee J, Raman S, Thompson J, et al. Improving physical realism, stereochemistry, and side-chain accuracy in homology modeling: Four approaches that performed well in CASP8. Proteins: Structure, Function and Bioinformatics. Proteins; 2009. pp. 114-122. doi:10.1002/prot.22570

25. M W, MJ S. ProSA-web: interactive web service for the recognition of errors in three-dimensional structures of proteins. Nucleic Acids Res. 2007;35.

doi:10.1093/NAR/GKM290

26. Zhang B, Ye W, Ye Y, Zhou H, Saeed AFUH, Chen J, et al. Structural insights into Cas13b-guided CRISPR RNA maturation and recognition. Cell Research. Cell Res; 2018. pp. 1198-1201. doi:10.1038/s41422-018-0109-4

27. Jumper J, Evans R, Pritzel A, Green T, Figurnov M, Ronneberger O, et al. Highly accurate protein structure prediction with AlphaFold. Nature. 2021;596: 583-589. doi:10.1038/s41586-021-03819-2

28. Gasteiger E, Hoogland C, Gattiker A, Duvaud S, Wilkins MR, Appel RD, et al. Protein Identification and Analysis Tools on the ExPASy Server. The Proteomics Protocols Handbook. Humana Press; 2005. pp. 571-607. doi:10.1385/1-59259-8900:571 
502 29. Jones DT, Cozzetto D. DISOPRED3: Precise disordered region predictions with $503 \quad$ annotated protein-binding activity. Bioinformatics. 2015;31: 857-863.

504 doi:10.1093/bioinformatics/btu744

505 30. Ward JJ, McGuffin LJ, Bryson K, Buxton BF, Jones DT. The DISOPRED server for 506 the prediction of protein disorder. Bioinformatics. 2004;20: 2138-2139. doi:10.1093/bioinformatics/bth195

508

31. Wiederstein M, Sippl MJ. ProSA-web: Interactive web service for the recognition of errors in three-dimensional structures of proteins. Nucleic Acids Res. 2007;35: W407-10. doi:10.1093/nar/gkm290

32. Laskowski RA, MacArthur MW, Moss DS, Thornton JM. PROCHECK: a program to check the stereochemical quality of protein structures. J Appl Crystallogr. 1993;26: 283-291. doi:10.1107/s0021889892009944

33. Zhang Y, Skolnick J. TM-align: A protein structure alignment algorithm based on the TM-score. Nucleic Acids Res. 2005;33: 2302-2309. doi:10.1093/nar/gki524

34. Zhang Y, Skolnick J. Scoring function for automated assessment of protein structure template quality. Proteins Struct Funct Genet. 2004;57: 702-710.

doi:10.1002/prot.20264

35. Yang J, Roy A, Zhang Y. Protein-ligand binding site recognition using complementary binding-specific substructure comparison and sequence profile alignment. Bioinformatics. 2013;29: 2588-2595. doi:10.1093/bioinformatics/btt447 
523

524

525

526

527

528

529

530

531

532

533

534

535

536

537

538

539

540

541 prediction by combining structure, sequence and protein-protein interaction information. Nucleic Acids Res. 2017;45: W291-W299. doi:10.1093/nar/gkx366

37. Lu S, Wang J, Chitsaz F, Derbyshire MK, Geer RC, Gonzales NR, et al.

CDD/SPARCLE: The conserved domain database in 2020. Nucleic Acids Res. 2020;48: D265-D268. doi:10.1093/nar/gkz991

38. Humphrey W, Dalke A, Schulten K. VMD: Visual molecular dynamics. J Mol Graph. 1996;14: 33-38. doi:10.1016/0263-7855(96)00018-5

39. Knapp B, Lederer N, Omasits U, Schreiner W. VmdICE: A plug-in for rapid evaluation of molecular dynamics simulations using VMD. J Comput Chem. 2010;31: 2868-2873. doi:10.1002/jcc.21581

40. Pettersen EF, Goddard TD, Huang CC, Couch GS, Greenblatt DM, Meng EC, et al. UCSF Chimera - A visualization system for exploratory research and analysis. J Comput Chem. 2004;25: 1605-1612. doi:10.1002/jcc.20084

41. Shannon P, Markiel A, Ozier O, Baliga NS, Wang JT, Ramage D, et al. Cytoscape: A software Environment for integrated models of biomolecular interaction networks. Genome Res. 2003;13: 2498-2504. doi:10.1101/gr.1239303

42. Doncheva NT, Klein K, Domingues FS, Albrecht M. Analyzing and visualizing residue networks of protein structures. Trends in Biochemical Sciences. Trends Biochem Sci; 2011.pp. 179-182. doi:10.1016/j.tibs.2011.01.002 
bioRxiv preprint doi: https://doi.org/10.1101/2021.11.11.468186; this version posted November 13, 2021. The copyright holder for this preprint (which was not certified by peer review) is the author/funder, who has granted bioRxiv a license to display the preprint in perpetuity. It is made available under aCC-BY 4.0 International license.

\section{Supporting information}

544 S 1 Fig. Sequence-based representation of the disordered and protein binding regions of

545 TTF1, as predicted using PsiPred.

546 S 2 Fig. Results of CD search indicating the presence of a SANT/Myb-like DNA-binding

547 domain in TTF1.

548 S 1 Table. Occupancy of the hydrogen bonds formed by the central residues throughout the 549 trajectory and in the last $50 \mathrm{~ns}$.

550

\begin{tabular}{|c|c|c|c|}
\hline Donor & Acceptor & Occupancy (200 ns) & Occupancy (last $50 \mathrm{~ns}$ ) \\
\hline K68*-Main & L67-Side & $75.34 \%$ & $85.41 \%$ \\
\hline A175-Main & A176*-Main & $76.84 \%$ & $78.12 \%$ \\
\hline R71*-Main & K68*-Main & $77.29 \%$ & $83.02 \%$ \\
\hline S197-Side & E195*-Side & $77.46 \%$ & $99.50 \%$ \\
\hline E27*-Main & I24-Main & $77.51 \%$ & $81.02 \%$ \\
\hline D471*-Main & A469-Main & $77.66 \%$ & $97.60 \%$ \\
\hline T896*-Main & N893*-Main & $78.04 \%$ & $97.60 \%$ \\
\hline E882*-Main & E880-Side & $78.41 \%$ & $94.21 \%$ \\
\hline D185-Side & N228*-Side & $78.66 \%$ & $82.72 \%$ \\
\hline S227-Side & R229*-Side & $79.01 \%$ & $119.18 \%$ \\
\hline K17*-Main & D16-Side & $79.29 \%$ & $91.01 \%$ \\
\hline R182*-Side & N228*-Side & $79.36 \%$ & $80.92 \%$ \\
\hline E431*-Main & A427-Main & $79.41 \%$ & $91.31 \%$ \\
\hline E209-Main & E206*-Main & $79.41 \%$ & $93.61 \%$ \\
\hline P437-Side & K434*-Main & $79.76 \%$ & $88.81 \%$ \\
\hline W198*-Side & G202*-Main & $79.94 \%$ & $81.72 \%$ \\
\hline I474-Main & D471*-Main & $79.99 \%$ & $90.11 \%$ \\
\hline S197-Main & W198*-Main & $80.58 \%$ & $83.12 \%$ \\
\hline A183-Main & R182*-Side & $81.46 \%$ & $75.82 \%$ \\
\hline F657*-Main & K656-Side & $82.58 \%$ & $87.91 \%$ \\
\hline E431*-Side & A427-Main & $82.83 \%$ & $117.98 \%$ \\
\hline K18-Main & K17*-Side & $83.03 \%$ & $99.00 \%$ \\
\hline P203-Side & W198*-Main & $83.56 \%$ & $125.27 \%$ \\
\hline E35*-Main & H34*-Side & $84.43 \%$ & $82.82 \%$ \\
\hline K31*-Side & E27*-Side & $84.46 \%$ & $125.47 \%$ \\
\hline F657*-Main & V653-Main & $84.53 \%$ & $82.52 \%$ \\
\hline R164*-Main & V163-Side & $85.01 \%$ & $94.91 \%$ \\
\hline K31*-Main & H32-Main & $85.61 \%$ & $86.21 \%$ \\
\hline E430-Main & E431*-Main & $85.63 \%$ & $90.91 \%$ \\
\hline A176*-Main & S177-Main & $86.01 \%$ & $82.12 \%$ \\
\hline S23*-Main & K19-Main & $86.01 \%$ & $100.00 \%$ \\
\hline Q30*-Side & E27*-Main & $86.23 \%$ & $87.21 \%$ \\
\hline S895*-Main & N893*-Side & $86.26 \%$ & $95.40 \%$ \\
\hline
\end{tabular}


bioRxiv preprint doi: https://doi.org/10.1101/2021.11.11.468186; this version posted November 13, 2021. The copyright holder for this preprint (which was not certified by peer review) is the author/funder, who has granted bioRxiv a license to display the preprint in perpetuity. It is made available under aCC-BY 4.0 International license.

\begin{tabular}{|c|c|c|c|}
\hline K656-Main & F657*-Main & $86.38 \%$ & $86.81 \%$ \\
\hline D471*-Main & S472-Main & $86.66 \%$ & $92.11 \%$ \\
\hline V433-Main & K434*-Main & $87.06 \%$ & $82.32 \%$ \\
\hline F657*-Side & V653-Main & $87.33 \%$ & $95.70 \%$ \\
\hline K434*-Main & S435*-Main & $87.43 \%$ & $94.61 \%$ \\
\hline S661-Side & F657*-Main & $87.91 \%$ & $78.82 \%$ \\
\hline S33-Main & Q30*-Main & $88.28 \%$ & $90.11 \%$ \\
\hline E27*-Main & R28-Main & $88.51 \%$ & $88.31 \%$ \\
\hline A176*-Main & Q172*-Main & $88.93 \%$ & $95.00 \%$ \\
\hline K31*-Side & E27*-Main & $89.63 \%$ & $85.31 \%$ \\
\hline R438-Main & S435*-Main & $89.68 \%$ & $94.11 \%$ \\
\hline D471*-Main & E467-Main & $89.81 \%$ & $90.51 \%$ \\
\hline I660*-Main & F657*-Main & $89.93 \%$ & $93.61 \%$ \\
\hline Q30*-Main & E27*-Main & $90.08 \%$ & $92.71 \%$ \\
\hline P188-Side & N228*-Main & $90.83 \%$ & $115.78 \%$ \\
\hline E431*-Main & G432-Main & $91.03 \%$ & $97.20 \%$ \\
\hline S435*-Main & E431*-Main & $91.05 \%$ & $94.61 \%$ \\
\hline R664*-Main & I660*-Main & $91.45 \%$ & $126.17 \%$ \\
\hline E882*-Main & S881-Side & $91.93 \%$ & $94.71 \%$ \\
\hline E35*-Main & I36-Main & $92.25 \%$ & $88.01 \%$ \\
\hline Q181-Side & R182*-Main & $92.65 \%$ & $87.61 \%$ \\
\hline T896*-Main & S895*-Side & $92.85 \%$ & $81.02 \%$ \\
\hline K68*-Main & S65-Main & $93.45 \%$ & $84.82 \%$ \\
\hline S435*-Main & K434*-Side & $93.58 \%$ & $96.20 \%$ \\
\hline R229*-Main & N228*-Side & $93.73 \%$ & $97.80 \%$ \\
\hline S661-Main & F657*-Main & $93.83 \%$ & $89.11 \%$ \\
\hline I660*-Main & S661-Main & $93.85 \%$ & $98.60 \%$ \\
\hline Q439-Main & S435*-Main & $93.88 \%$ & $92.51 \%$ \\
\hline G901-Main & G899*-Main & $94.28 \%$ & $99.50 \%$ \\
\hline E27*-Main & S23*-Main & $94.65 \%$ & $94.31 \%$ \\
\hline A176*-Main & A175-Side & $94.73 \%$ & $97.70 \%$ \\
\hline R71*-Main & S70-Side & $95.15 \%$ & $114.89 \%$ \\
\hline S472-Main & D471*-Side & $95.33 \%$ & $93.91 \%$ \\
\hline Q30*-Main & K31*-Main & $95.33 \%$ & $96.20 \%$ \\
\hline I36-Main & E35*-Side & $95.38 \%$ & $92.11 \%$ \\
\hline L62-Side & H34*-Main & $95.68 \%$ & $112.79 \%$ \\
\hline E35*-Main & H32-Main & $96.10 \%$ & $91.71 \%$ \\
\hline R436-Main & K434*-Main & $96.93 \%$ & $93.11 \%$ \\
\hline S190-Main & E191*-Main & $97.15 \%$ & $97.20 \%$ \\
\hline E470-Main & D471*-Main & $97.18 \%$ & $95.40 \%$ \\
\hline E27*-Main & K26-Side & $97.50 \%$ & $96.80 \%$ \\
\hline K26-Main & S23*-Main & $97.68 \%$ & $98.20 \%$ \\
\hline H34*-Main & E35*-Main & $97.73 \%$ & $95.90 \%$ \\
\hline I36-Main & H34*-Main & $98.10 \%$ & $123.08 \%$ \\
\hline G432-Main & E431*-Side & $98.18 \%$ & $98.50 \%$ \\
\hline K166-Main & E165*-Side & $98.18 \%$ & $99.30 \%$ \\
\hline S435*-Main & R436-Main & $98.25 \%$ & $96.60 \%$ \\
\hline D471*-Main & E470-Side & $98.43 \%$ & $97.00 \%$ \\
\hline R173-Main & Q172*-Side & $98.45 \%$ & $104.40 \%$ \\
\hline L67-Main & K68*-Main & $98.55 \%$ & $96.60 \%$ \\
\hline S200-Main & E196*-Main & $98.70 \%$ & $96.50 \%$ \\
\hline N228*-Main & T186*-Main & $99.08 \%$ & $99.90 \%$ \\
\hline L199-Main & E195*-Main & $99.18 \%$ & $99.40 \%$ \\
\hline T896*-Main & L897-Main & $99.30 \%$ & $96.60 \%$ \\
\hline W198*-Main & E195*-Main & $99.30 \%$ & $99.50 \%$ \\
\hline E195*-Main & Q194-Side & $99.50 \%$ & $99.40 \%$ \\
\hline V201-Main & W198*-Main & $99.55 \%$ & $99.10 \%$ \\
\hline
\end{tabular}


bioRxiv preprint doi: https://doi.org/10.1101/2021.11.11.468186; this version posted November 13, 2021. The copyright holder for this preprint (which was not certified by peer review) is the author/funder, who has granted bioRxiv a license to display the preprint in perpetuity. It is made available under aCC-BY 4.0 International license.

\begin{tabular}{|c|c|c|c|}
\hline W903-Main & R902*-Side & $99.75 \%$ & $100.30 \%$ \\
\hline W198*-Main & L199-Main & $99.80 \%$ & $100.00 \%$ \\
\hline K31*-Main & E27*-Main & $99.85 \%$ & $99.60 \%$ \\
\hline T186*-Main & D185-Side & $99.90 \%$ & $99.90 \%$ \\
\hline E195*-Main & K700-Main & $99.98 \%$ & $99.70 \%$ \\
\hline D185-Main & T186*-Main & $100.00 \%$ & $100.00 \%$ \\
\hline E165*-Main & K166-Main & $100.02 \%$ & $100.00 \%$ \\
\hline T186*-Main & L187-Main & $100.02 \%$ & $100.10 \%$ \\
\hline E195*-Main & E196*-Main & $100.05 \%$ & $100.10 \%$ \\
\hline E230-Main & R229*-Side & $100.07 \%$ & $96.80 \%$ \\
\hline Q194-Main & E195*-Main & $100.07 \%$ & $100.00 \%$ \\
\hline H160-Main & S161*-Main & $100.07 \%$ & $100.10 \%$ \\
\hline C892-Main & N893*-Main & $100.22 \%$ & $100.20 \%$ \\
\hline R164*-Main & E165*-Main & $100.27 \%$ & $100.20 \%$ \\
\hline R71*-Main & I72-Main & $100.55 \%$ & $101.20 \%$ \\
\hline K26-Main & E27*-Main & $100.57 \%$ & $100.40 \%$ \\
\hline S161*-Main & K162-Main & $101.10 \%$ & $100.10 \%$ \\
\hline K31*-Main & Q30*-Side & $101.15 \%$ & $101.80 \%$ \\
\hline C22-Main & S23*-Main & $101.20 \%$ & $105.19 \%$ \\
\hline R229*-Main & E230-Main & $101.22 \%$ & $101.90 \%$ \\
\hline E95-Main & L94-Side & $101.35 \%$ & $104.10 \%$ \\
\hline D39-Main & R38*-Side & $101.55 \%$ & $102.80 \%$ \\
\hline Q30*-Side & K31*-Main & $101.65 \%$ & $102.90 \%$ \\
\hline F37-Main & R38*-Main & $101.97 \%$ & $114.59 \%$ \\
\hline S227-Side & N228*-Main & $102.00 \%$ & $97.30 \%$ \\
\hline N228*-Main & R229*-Main & $102.32 \%$ & $100.20 \%$ \\
\hline S23*-Main & C22-Side & $102.35 \%$ & $94.41 \%$ \\
\hline R436-Main & S435*-Side & $102.40 \%$ & $94.01 \%$ \\
\hline V163-Side & R164*-Main & $102.45 \%$ & $96.60 \%$ \\
\hline V201-Main & G202*-Main & $102.62 \%$ & $103.70 \%$ \\
\hline K17*-Main & K18-Main & $102.80 \%$ & $96.40 \%$ \\
\hline E430-Side & E431*-Main & $102.85 \%$ & $93.61 \%$ \\
\hline R182*-Side & A176*-Main & $102.90 \%$ & $130.57 \%$ \\
\hline K166-Main & E165*-Main & $103.42 \%$ & $102.20 \%$ \\
\hline S192-Main & E191*-Side & $103.70 \%$ & $96.40 \%$ \\
\hline N893*-Main & S894-Main & $104.27 \%$ & $104.10 \%$ \\
\hline S33-Side & Q30*-Main & $104.37 \%$ & $95.00 \%$ \\
\hline K68*-Main & K69-Main & $104.37 \%$ & $98.50 \%$ \\
\hline F657*-Main & S658-Main & $104.40 \%$ & $100.70 \%$ \\
\hline L67-Side & K68*-Main & $104.57 \%$ & $144.26 \%$ \\
\hline S70-Main & R71*-Main & $104.70 \%$ & $95.10 \%$ \\
\hline E191*-Main & S190-Side & $105.00 \%$ & $102.60 \%$ \\
\hline G899*-Main & L897-Main & $105.77 \%$ & $158.34 \%$ \\
\hline H32-Main & K31*-Side & $105.95 \%$ & $100.10 \%$ \\
\hline H171-Main & Q172*-Main & $106.65 \%$ & $101.40 \%$ \\
\hline L897-Main & S895*-Main & $106.80 \%$ & $133.17 \%$ \\
\hline S895*-Side & E165*-Side & $106.85 \%$ & $204.70 \%$ \\
\hline Q663-Main & R664*-Main & $107.02 \%$ & $117.68 \%$ \\
\hline S881-Side & E882*-Main & $107.50 \%$ & $138.56 \%$ \\
\hline E35*-Main & S33-Main & $107.55 \%$ & $100.40 \%$ \\
\hline E431*-Main & E430-Side & $107.60 \%$ & $113.99 \%$ \\
\hline R902*-Main & W903-Main & $107.62 \%$ & $104.10 \%$ \\
\hline K225-Main & S226*-Main & $107.67 \%$ & $107.29 \%$ \\
\hline S161*-Main & H160-Side & $109.75 \%$ & $95.40 \%$ \\
\hline R28-Main & E27*-Side & $110.17 \%$ & $107.49 \%$ \\
\hline S881-Main & E882*-Main & $111.24 \%$ & $105.79 \%$ \\
\hline E882*-Main & G883-Main & $111.49 \%$ & $115.68 \%$ \\
\hline
\end{tabular}


bioRxiv preprint doi: https://doi.org/10.1101/2021.11.11.468186; this version posted November 13, 2021. The copyright holder for this preprint (which was not certified by peer review) is the author/funder, who has granted bioRxiv a license to display the preprint in perpetuity. It is made available under aCC-BY 4.0 International license.

\begin{tabular}{|c|c|c|c|}
\hline K434*-Main & V433-Side & $111.57 \%$ & $127.37 \%$ \\
\hline K434*-Side & Q663-Main & $111.84 \%$ & $118.18 \%$ \\
\hline S227-Main & N228*-Main & $113.14 \%$ & $115.48 \%$ \\
\hline Q30*-Main & P29-Side & $113.47 \%$ & $113.29 \%$ \\
\hline S435*-Main & V433-Main & $114.04 \%$ & $104.90 \%$ \\
\hline S226*-Main & K224-Main & $114.97 \%$ & $136.76 \%$ \\
\hline K174-Main & Q172*-Main & $115.02 \%$ & $127.67 \%$ \\
\hline K879-Side & R902*-Side & $115.34 \%$ & $217.68 \%$ \\
\hline S895*-Side & T896*-Main & $115.49 \%$ & $80.92 \%$ \\
\hline S661-Main & I660*-Side & $115.52 \%$ & $124.58 \%$ \\
\hline R902*-Main & Q900-Main & $116.44 \%$ & $129.77 \%$ \\
\hline I660*-Main & Q659-Side & $116.72 \%$ & $140.86 \%$ \\
\hline E165*-Main & R164*-Side & $117.87 \%$ & $159.94 \%$ \\
\hline S40-Main & R38*-Main & $117.89 \%$ & $130.77 \%$ \\
\hline K434*-Main & G432-Main & $118.02 \%$ & $156.04 \%$ \\
\hline V433-Main & E431*-Main & $118.04 \%$ & $109.99 \%$ \\
\hline R38*-Side & E35*-Main & $118.32 \%$ & $105.09 \%$ \\
\hline N893*-Side & R164*-Side & $118.77 \%$ & $215.38 \%$ \\
\hline F37-Main & E35*-Main & $118.79 \%$ & $126.77 \%$ \\
\hline W198*-Side & L199-Main & $119.27 \%$ & $118.88 \%$ \\
\hline A176*-Side & Q172*-Main & $119.49 \%$ & $89.71 \%$ \\
\hline F657*-Side & A454-Main & $119.77 \%$ & $171.13 \%$ \\
\hline S435*-Side & R436-Main & $120.59 \%$ & $144.56 \%$ \\
\hline R902*-Side & K879-Side & $120.66 \%$ & $247.15 \%$ \\
\hline V433-Side & K434*-Main & $120.76 \%$ & $134.97 \%$ \\
\hline R184-Main & R182*-Main & $120.99 \%$ & $114.99 \%$ \\
\hline H34*-Main & S33-Side & $122.36 \%$ & $111.69 \%$ \\
\hline E431*-Main & M429-Main & $122.46 \%$ & $117.48 \%$ \\
\hline S70-Side & R71*-Main & $122.59 \%$ & $123.88 \%$ \\
\hline T896*-Side & N893*-Main & $123.06 \%$ & $208.99 \%$ \\
\hline K68*-Main & P66-Main & $126.81 \%$ & $99.40 \%$ \\
\hline P29-Side & Q30*-Main & $127.76 \%$ & $125.87 \%$ \\
\hline I660*-Side & S661-Main & $127.76 \%$ & $135.36 \%$ \\
\hline R164*-Side & N893*-Side & $128.19 \%$ & $248.15 \%$ \\
\hline I660*-Main & S658-Main & $128.79 \%$ & $173.53 \%$ \\
\hline Q172*-Side & K803-Main & $129.04 \%$ & $122.78 \%$ \\
\hline R38*-Main & I36-Main & $129.06 \%$ & $104.90 \%$ \\
\hline K68*-Side & K69-Main & $129.29 \%$ & $105.89 \%$ \\
\hline S33-Main & K31*-Main & $131.36 \%$ & $139.16 \%$ \\
\hline S662-Main & I660*-Main & $131.58 \%$ & $86.01 \%$ \\
\hline G202*-Main & W198*-Side & $134.06 \%$ & $118.28 \%$ \\
\hline E206*-Main & G204-Main & $134.06 \%$ & $186.01 \%$ \\
\hline N893*-Main & C892-Side & $134.31 \%$ & $126.77 \%$ \\
\hline G205-Main & E206*-Main & $134.93 \%$ & $118.18 \%$ \\
\hline E35*-Side & I36-Main & $135.38 \%$ & $125.47 \%$ \\
\hline E191*-Side & S192-Main & $135.86 \%$ & $145.65 \%$ \\
\hline K17*-Side & K18-Main & $136.01 \%$ & $134.17 \%$ \\
\hline V163-Main & R164*-Main & $136.38 \%$ & $148.45 \%$ \\
\hline R38*-Side & D39-Main & $136.88 \%$ & $107.79 \%$ \\
\hline E196*-Side & S197-Main & $137.48 \%$ & $136.06 \%$ \\
\hline H160-Side & S161*-Main & $137.56 \%$ & $185.51 \%$ \\
\hline R182*-Side & A183-Main & $137.63 \%$ & $136.76 \%$ \\
\hline C22-Side & S23*-Main & $137.98 \%$ & $153.55 \%$ \\
\hline S197-Main & E196*-Side & $138.01 \%$ & $107.19 \%$ \\
\hline R71*-Side & I72-Main & $138.53 \%$ & $132.07 \%$ \\
\hline R664*-Main & N665-Main & $138.96 \%$ & $156.54 \%$ \\
\hline S197-Side & W198*-Main & $139.06 \%$ & $130.97 \%$ \\
\hline
\end{tabular}


bioRxiv preprint doi: https://doi.org/10.1101/2021.11.11.468186; this version posted November 13, 2021. The copyright holder for this preprint (which was not certified by peer review) is the author/funder, who has granted bioRxiv a license to display the preprint in perpetuity. It is made available under aCC-BY 4.0 International license.

\begin{tabular}{|c|c|c|c|}
\hline G202*-Main & W198*-Main & $139.33 \%$ & $141.26 \%$ \\
\hline A176*-Side & S177-Main & $139.86 \%$ & $141.46 \%$ \\
\hline W198*-Side & S699-Side & $141.23 \%$ & $190.21 \%$ \\
\hline E431*-Side & G432-Main & $141.73 \%$ & $172.33 \%$ \\
\hline S895*-Side & N893*-Side & $141.73 \%$ & $173.23 \%$ \\
\hline S894-Side & S895*-Main & $143.00 \%$ & $136.36 \%$ \\
\hline D16-Side & K17*-Main & $143.30 \%$ & $147.75 \%$ \\
\hline K656-Side & F657*-Main & $143.50 \%$ & $157.84 \%$ \\
\hline E473-Main & D471*-Main & $143.68 \%$ & $156.84 \%$ \\
\hline S895*-Main & S894-Side & $145.23 \%$ & $128.37 \%$ \\
\hline F657*-Main & L655-Main & $145.63 \%$ & $145.45 \%$ \\
\hline R229*-Side & S227-Side & $145.80 \%$ & $215.18 \%$ \\
\hline S161*-Side & K162-Main & $146.63 \%$ & $154.05 \%$ \\
\hline Q663-Side & R664*-Main & $146.88 \%$ & $101.10 \%$ \\
\hline I24-Main & S23*-Side & $146.90 \%$ & $160.14 \%$ \\
\hline S435*-Side & E431*-Main & $146.98 \%$ & $139.66 \%$ \\
\hline S23*-Side & I24-Main & $148.58 \%$ & $131.57 \%$ \\
\hline T896*-Side & L897-Main & $148.63 \%$ & $178.42 \%$ \\
\hline H32-Main & Q30*-Main & $148.75 \%$ & $144.16 \%$ \\
\hline K434*-Side & S435*-Main & $149.48 \%$ & $165.43 \%$ \\
\hline S894-Main & N893*-Side & $150.75 \%$ & $151.95 \%$ \\
\hline W198*-Main & S197-Side & $151.25 \%$ & $157.04 \%$ \\
\hline L897-Main & T896*-Side & $152.00 \%$ & $182.52 \%$ \\
\hline Q194-Side & E195*-Main & $152.55 \%$ & $155.44 \%$ \\
\hline R902*-Side & T896*-Main & $152.85 \%$ & $236.46 \%$ \\
\hline A176*-Main & K174-Main & $153.85 \%$ & $155.94 \%$ \\
\hline D471*-Side & S472-Main & $154.42 \%$ & $129.07 \%$ \\
\hline E470-Side & D471*-Main & $154.82 \%$ & $117.38 \%$ \\
\hline K167-Main & E165*-Main & $154.90 \%$ & $170.13 \%$ \\
\hline Q659-Side & I660*-Main & $156.85 \%$ & $186.51 \%$ \\
\hline G202*-Main & V201-Side & $157.22 \%$ & $152.05 \%$ \\
\hline K31*-Side & H32-Main & $157.72 \%$ & $183.82 \%$ \\
\hline G898-Main & G899*-Main & $158.45 \%$ & $136.66 \%$ \\
\hline Q30*-Main & R28-Main & $159.10 \%$ & $163.44 \%$ \\
\hline L199-Main & W198*-Side & $159.12 \%$ & $164.04 \%$ \\
\hline S33-Side & H34*-Main & $159.62 \%$ & $156.54 \%$ \\
\hline E206*-Side & I207-Main & $159.67 \%$ & $127.57 \%$ \\
\hline V201-Side & G202*-Main & $159.82 \%$ & $169.03 \%$ \\
\hline H193-Main & E191*-Main & $160.04 \%$ & $161.24 \%$ \\
\hline T208-Main & E206*-Main & $160.74 \%$ & $192.31 \%$ \\
\hline S70-Main & K68*-Main & $161.44 \%$ & $179.72 \%$ \\
\hline H34*-Main & H32-Main & $163.47 \%$ & $161.64 \%$ \\
\hline Q30*-Side & R71*-Main & $165.09 \%$ & $194.81 \%$ \\
\hline R164*-Side & V163-Main & $166.04 \%$ & $191.01 \%$ \\
\hline W198*-Main & E196*-Main & $167.82 \%$ & $178.82 \%$ \\
\hline K162-Main & S161*-Side & $168.42 \%$ & $177.02 \%$ \\
\hline K17*-Main & S15-Main & $168.49 \%$ & $147.05 \%$ \\
\hline C892-Side & N893*-Main & $168.52 \%$ & $151.65 \%$ \\
\hline H34*-Side & E35*-Main & $168.84 \%$ & $165.63 \%$ \\
\hline D185-Side & T186*-Main & $169.34 \%$ & $169.83 \%$ \\
\hline Q659-Main & F657*-Main & $171.14 \%$ & $183.42 \%$ \\
\hline S190-Side & E191*-Main & $171.89 \%$ & $188.21 \%$ \\
\hline S226*-Main & S227-Main & $171.91 \%$ & $160.04 \%$ \\
\hline K391-Side & E431*-Side & $173.11 \%$ & $525.57 \%$ \\
\hline Q172*-Main & H171-Side & $174.26 \%$ & $173.13 \%$ \\
\hline K26-Side & E27*-Main & $174.71 \%$ & $170.13 \%$ \\
\hline W178-Main & A176*-Main & $174.79 \%$ & $172.33 \%$ \\
\hline
\end{tabular}


bioRxiv preprint doi: https://doi.org/10.1101/2021.11.11.468186; this version posted November 13, 2021. The copyright holder for this preprint (which was not certified by peer review) is the author/funder, who has granted bioRxiv a license to display the preprint in perpetuity. It is made available under aCC-BY 4.0 International license.

\begin{tabular}{|c|c|c|c|}
\hline S200-Side & E196*-Main & $175.24 \%$ & $167.83 \%$ \\
\hline T896*-Main & S894-Main & $175.56 \%$ & $184.32 \%$ \\
\hline G901-Main & R902*-Main & $175.79 \%$ & $185.51 \%$ \\
\hline E27*-Side & R28-Main & $176.59 \%$ & $143.36 \%$ \\
\hline R664*-Side & E453-Side & $177.26 \%$ & $163.94 \%$ \\
\hline R229*-Side & E230-Main & $178.89 \%$ & $193.61 \%$ \\
\hline E195*-Side & E196*-Main & $181.06 \%$ & $179.82 \%$ \\
\hline N228*-Main & S227-Side & $181.73 \%$ & $188.41 \%$ \\
\hline R164*-Side & E882*-Side & $182.91 \%$ & $338.56 \%$ \\
\hline K434*-Side & E430-Main & $183.93 \%$ & $255.14 \%$ \\
\hline S895*-Main & N893*-Main & $184.93 \%$ & $197.50 \%$ \\
\hline N228*-Side & R229*-Main & $185.01 \%$ & $193.71 \%$ \\
\hline L187-Main & T186*-Side & $185.56 \%$ & $190.91 \%$ \\
\hline R902*-Side & W903-Main & $186.46 \%$ & $191.41 \%$ \\
\hline Q172*-Side & R173-Main & $186.56 \%$ & $181.12 \%$ \\
\hline R164*-Side & E165*-Main & $187.01 \%$ & $173.33 \%$ \\
\hline A175-Side & A176*-Main & $188.11 \%$ & $193.61 \%$ \\
\hline H25-Main & S23*-Main & $189.38 \%$ & $194.61 \%$ \\
\hline W198*-Side & Q194-Side & $190.18 \%$ & $201.00 \%$ \\
\hline G202*-Main & P203-Main & $190.80 \%$ & $196.10 \%$ \\
\hline K17*-Side & E206*-Side & $192.30 \%$ & $445.15 \%$ \\
\hline S197-Main & E195*-Main & $193.05 \%$ & $194.41 \%$ \\
\hline G899*-Main & Q900-Main & $194.33 \%$ & $200.00 \%$ \\
\hline E165*-Side & K166-Main & $194.58 \%$ & $198.40 \%$ \\
\hline R182*-Main & S180-Main & $194.80 \%$ & $195.40 \%$ \\
\hline N228*-Side & T186*-Main & $197.88 \%$ & $215.28 \%$ \\
\hline S200-Main & W198*-Main & $199.08 \%$ & $198.20 \%$ \\
\hline G202*-Main & P203-Side & $199.68 \%$ & $200.00 \%$ \\
\hline P203-Main & G202*-Main & $200.00 \%$ & $200.00 \%$ \\
\hline S226*-Main & K225-Main & $200.12 \%$ & $200.20 \%$ \\
\hline R902*-Side & G901-Main & $204.92 \%$ & $249.75 \%$ \\
\hline S649-Side & D471*-Side & $208.30 \%$ & $151.15 \%$ \\
\hline K166-Side & E165*-Main & $214.44 \%$ & $215.08 \%$ \\
\hline S699-Side & W198*-Side & $215.84 \%$ & $262.04 \%$ \\
\hline R664*-Main & Q663-Main & $217.54 \%$ & $200.20 \%$ \\
\hline K434*-Side & E431*-Side & $222.09 \%$ & $399.30 \%$ \\
\hline K17*-Side & P13-Main & $224.49 \%$ & $154.05 \%$ \\
\hline S226*-Side & K225-Main & $227.46 \%$ & $213.69 \%$ \\
\hline K69-Side & E35*-Side & $229.14 \%$ & $129.47 \%$ \\
\hline E196*-Main & E195*-Side & $237.91 \%$ & $280.82 \%$ \\
\hline K17*-Side & P203-Main & $239.81 \%$ & $142.26 \%$ \\
\hline N228*-Side & D185-Main & $240.05 \%$ & $254.15 \%$ \\
\hline R664*-Side & Q663-Main & $248.33 \%$ & $260.14 \%$ \\
\hline N615-Side & D471*-Side & $252.77 \%$ & $228.37 \%$ \\
\hline K17*-Side & G204-Main & $275.61 \%$ & $254.55 \%$ \\
\hline S227-Side & E191*-Side & $276.89 \%$ & $290.61 \%$ \\
\hline K17*-Side & V201-Main & $277.41 \%$ & $122.28 \%$ \\
\hline S227-Side & S226*-Main & $278.39 \%$ & $270.13 \%$ \\
\hline R71*-Side & E9-Side & $284.26 \%$ & $79.12 \%$ \\
\hline K434*-Side & E430-Side & $288.83 \%$ & $660.24 \%$ \\
\hline K17*-Side & G202*-Main & $295.48 \%$ & $306.79 \%$ \\
\hline T186*-Main & D185-Main & $300.47 \%$ & $300.50 \%$ \\
\hline E195*-Main & Q194-Main & $301.10 \%$ & $301.20 \%$ \\
\hline E165*-Main & R164*-Main & $301.17 \%$ & $300.40 \%$ \\
\hline E196*-Main & E195*-Main & $301.75 \%$ & $300.40 \%$ \\
\hline N893*-Main & C892-Main & $304.20 \%$ & $309.79 \%$ \\
\hline L187-Main & T186*-Main & $304.65 \%$ & $302.40 \%$ \\
\hline
\end{tabular}


bioRxiv preprint doi: https://doi.org/10.1101/2021.11.11.468186; this version posted November 13, 2021. The copyright holder for this preprint (which was not certified by peer review) is the author/funder, who has granted bioRxiv a license to display the preprint in perpetuity. It is made available under aCC-BY 4.0 International license.

\begin{tabular}{|c|c|c|c|}
\hline R229*-Main & N228*-Main & $305.92 \%$ & $302.10 \%$ \\
\hline S161*-Main & H160-Main & $306.82 \%$ & $306.69 \%$ \\
\hline W903-Main & R902*-Main & $308.55 \%$ & $304.20 \%$ \\
\hline K162-Main & S161*-Main & $312.37 \%$ & $312.69 \%$ \\
\hline Q900-Main & G899*-Main & $312.69 \%$ & $300.00 \%$ \\
\hline N228*-Main & S227-Main & $313.14 \%$ & $315.48 \%$ \\
\hline R164*-Side & E880-Side & $313.72 \%$ & $552.85 \%$ \\
\hline Q172*-Main & H171-Main & $336.23 \%$ & $334.97 \%$ \\
\hline I72-Main & R71*-Main & $338.01 \%$ & $341.26 \%$ \\
\hline E206*-Main & G205-Main & $340.43 \%$ & $400.00 \%$ \\
\hline S894-Main & N893*-Main & $349.65 \%$ & $346.95 \%$ \\
\hline T186*-Side & L187-Main & $359.20 \%$ & $397.00 \%$ \\
\hline R164*-Main & V163-Main & $366.74 \%$ & $361.24 \%$ \\
\hline R902*-Side & E869-Side & $380.26 \%$ & $562.74 \%$ \\
\hline R902*-Main & G901-Main & $384.53 \%$ & $400.00 \%$ \\
\hline R229*-Side & E191*-Side & $388.03 \%$ & $500.00 \%$ \\
\hline R182*-Side & E232-Main & $389.63 \%$ & $413.49 \%$ \\
\hline N665-Main & R664*-Main & $392.23 \%$ & $400.00 \%$ \\
\hline G432-Main & E431*-Main & $399.93 \%$ & $399.90 \%$ \\
\hline R38*-Main & F37-Main & $399.95 \%$ & $400.00 \%$ \\
\hline L897-Main & T896*-Main & $400.00 \%$ & $400.00 \%$ \\
\hline T896*-Main & S895*-Main & $400.00 \%$ & $400.00 \%$ \\
\hline S895*-Main & S894-Main & $400.00 \%$ & $400.00 \%$ \\
\hline E882*-Main & S881-Main & $400.00 \%$ & $400.00 \%$ \\
\hline R173-Main & Q172*-Main & $400.00 \%$ & $400.00 \%$ \\
\hline E27*-Main & K26-Main & $400.00 \%$ & $400.00 \%$ \\
\hline Q30*-Main & P29-Main & $400.00 \%$ & $400.00 \%$ \\
\hline R28-Main & E27*-Main & $400.00 \%$ & $400.00 \%$ \\
\hline S23*-Main & C22-Main & $400.00 \%$ & $400.00 \%$ \\
\hline I24-Main & S23*-Main & $400.00 \%$ & $400.00 \%$ \\
\hline H34*-Main & S33-Main & $400.00 \%$ & $400.00 \%$ \\
\hline E35*-Main & H34*-Main & $400.00 \%$ & $400.00 \%$ \\
\hline K31*-Main & Q30*-Main & $400.00 \%$ & $400.00 \%$ \\
\hline H32-Main & K31*-Main & $400.00 \%$ & $400.00 \%$ \\
\hline I36-Main & E35*-Main & $400.00 \%$ & $400.00 \%$ \\
\hline A176*-Main & A175-Main & $400.00 \%$ & $400.00 \%$ \\
\hline S177-Main & A176*-Main & $400.00 \%$ & $400.00 \%$ \\
\hline K69-Main & K68*-Main & $400.00 \%$ & $400.00 \%$ \\
\hline R71*-Main & S70-Main & $400.00 \%$ & $400.00 \%$ \\
\hline S227-Main & S226*-Main & $400.00 \%$ & $400.00 \%$ \\
\hline I207-Main & E206*-Main & $400.00 \%$ & $400.00 \%$ \\
\hline K17*-Main & D16-Main & $400.00 \%$ & $400.00 \%$ \\
\hline K18-Main & K17*-Main & $400.00 \%$ & $400.00 \%$ \\
\hline K68*-Main & L67-Main & $400.00 \%$ & $400.00 \%$ \\
\hline D39-Main & R38*-Main & $400.00 \%$ & $400.00 \%$ \\
\hline E230-Main & R229*-Main & $400.00 \%$ & $400.00 \%$ \\
\hline R182*-Main & Q181-Main & $400.00 \%$ & $400.00 \%$ \\
\hline A183-Main & R182*-Main & $400.00 \%$ & $400.00 \%$ \\
\hline L199-Main & W198*-Main & $400.00 \%$ & $400.00 \%$ \\
\hline S192-Main & E191*-Main & $400.00 \%$ & $400.00 \%$ \\
\hline E191*-Main & S190-Main & $400.00 \%$ & $400.00 \%$ \\
\hline W198*-Main & S197-Main & $400.00 \%$ & $400.00 \%$ \\
\hline S197-Main & E196*-Main & $400.00 \%$ & $400.00 \%$ \\
\hline E431*-Main & E430-Main & $400.00 \%$ & $400.00 \%$ \\
\hline R436-Main & S435*-Main & $400.00 \%$ & $400.00 \%$ \\
\hline S435*-Main & K434*-Main & $400.00 \%$ & $400.00 \%$ \\
\hline K434*-Main & V433-Main & $400.00 \%$ & $400.00 \%$ \\
\hline
\end{tabular}


bioRxiv preprint doi: https://doi.org/10.1101/2021.11.11.468186; this version posted November 13, 2021. The copyright holder for this preprint (which was not certified by peer review) is the author/funder, who has granted bioRxiv a license to display the preprint in perpetuity. It is made available under aCC-BY 4.0 International license.

36

\begin{tabular}{|l|l|l|l|}
\hline S658-Main & F657*-Main & $400.00 \%$ & $400.00 \%$ \\
\hline I660*-Main & Q659-Main & $400.00 \%$ & $400.00 \%$ \\
\hline F657*-Main & K656-Main & $400.00 \%$ & $400.00 \%$ \\
\hline S661-Main & I660*-Main & $400.00 \%$ & $400.00 \%$ \\
\hline D471*-Main & E470-Main & $400.00 \%$ & $400.00 \%$ \\
\hline S472-Main & D471*-Main & $400.00 \%$ & $400.00 \%$ \\
\hline G899*-Main & G898-Main & $400.10 \%$ & $401.00 \%$ \\
\hline G202*-Main & V201-Main & $400.82 \%$ & $403.30 \%$ \\
\hline R38*-Side & E35*-Side & $406.17 \%$ & $385.11 \%$ \\
\hline R229*-Side & N228*-Main & $421.29 \%$ & $512.19 \%$ \\
\hline R164*-Side & E165*-Side & $457.75 \%$ & $489.11 \%$ \\
\hline G883-Main & E882*-Main & $472.74 \%$ & $561.44 \%$ \\
\hline K20-Side & E27*-Side & $530.31 \%$ & $389.51 \%$ \\
\hline P203-Side & G202*-Main & $601.07 \%$ & $602.20 \%$ \\
\hline K765-Side & E206*-Side & $655.37 \%$ & $665.53 \%$ \\
\hline
\end{tabular}

551 The central residues are marked by *. Side and Main indicate whether the hydrogen bond was formed with an atom of the

552 side chain or the main chain, respectively. Occupancies $>100 \%$ indicate the formation of more than one inter-residue

553 hydrogen bond. 


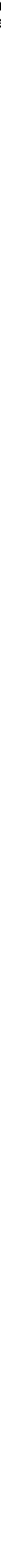

Fig 3 


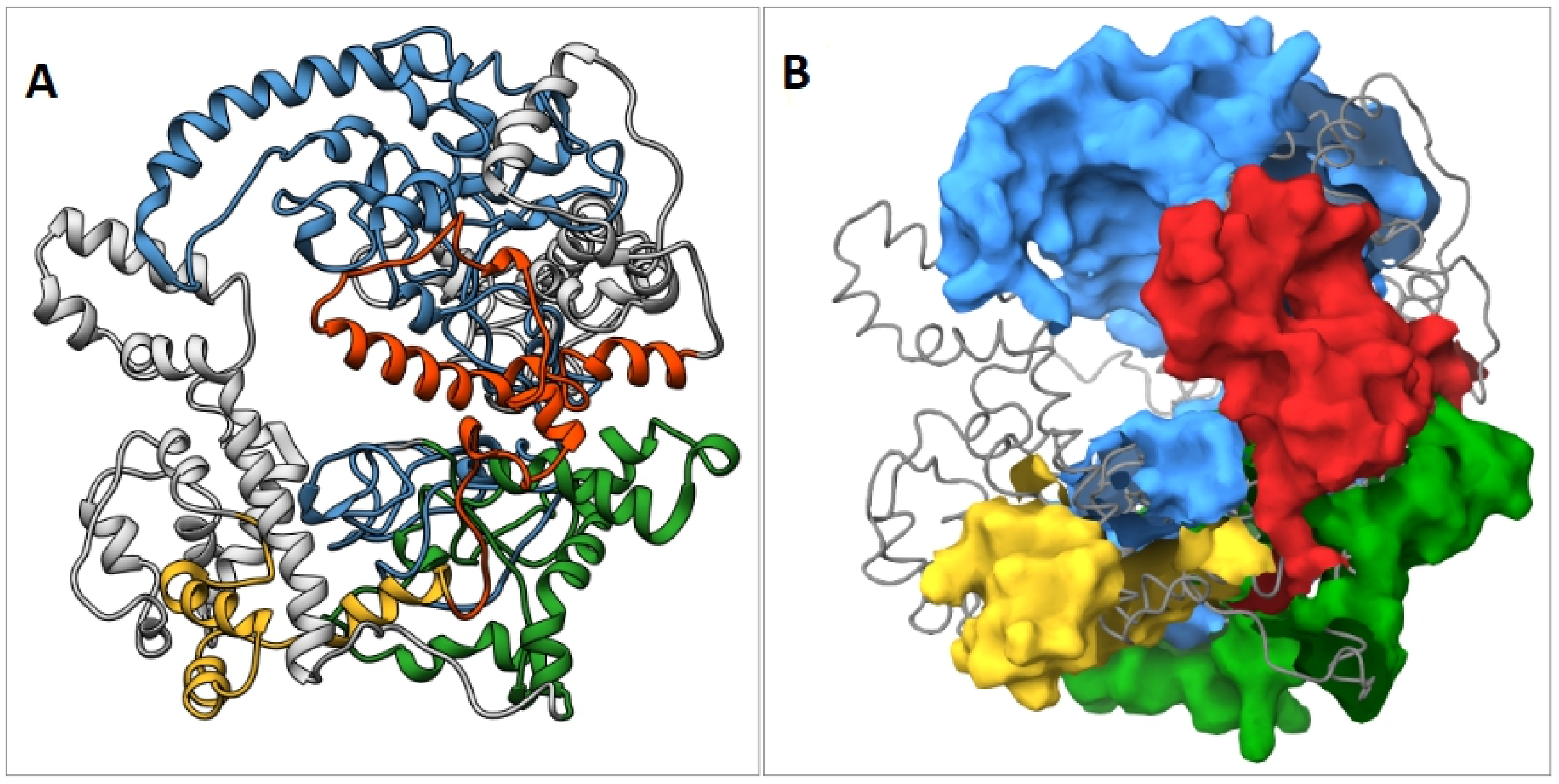

Fig 5 


\section{Disorder score}

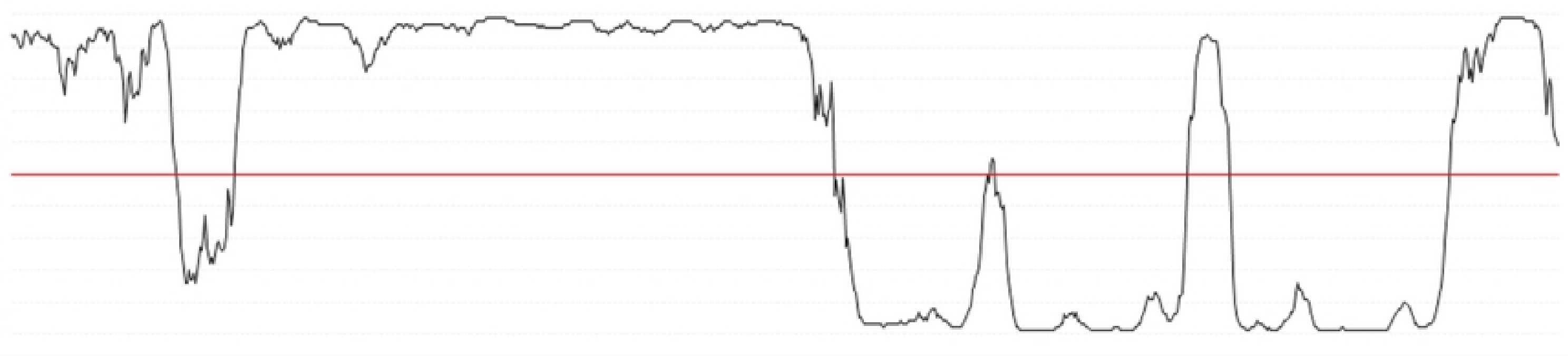

Fig 1 
A
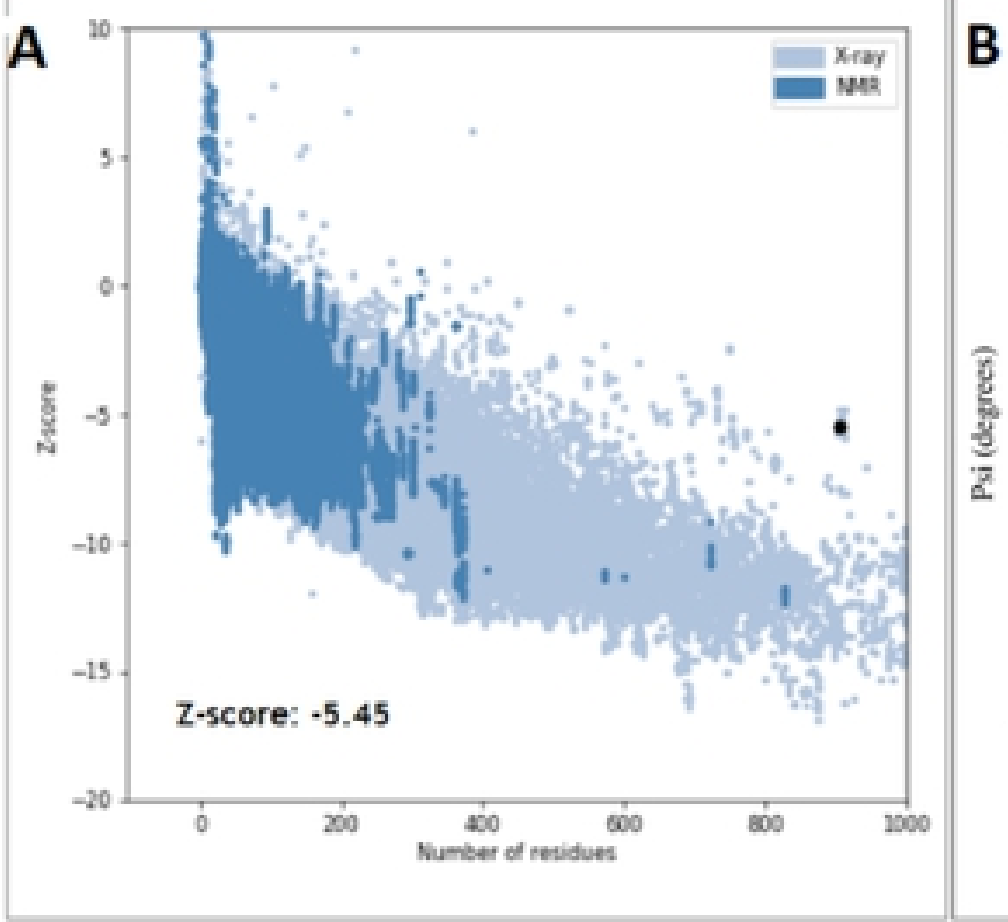

B

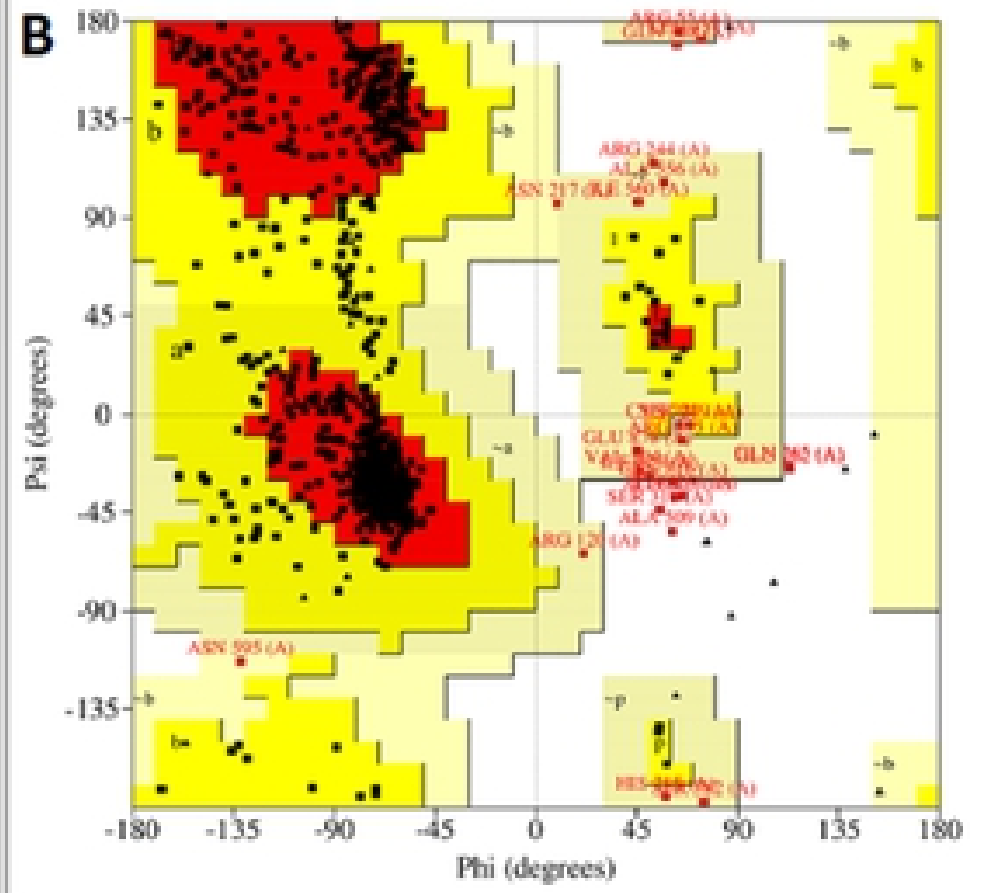

Residues in most favoured regions [A,B,L]

Residues in additional allowed regions $[a, b, l, p]$

Residues in generously allowed regions $[\sim a,-b, \sim 1, \sim p]$

Residues in disallowed regions

Number of non-glycine and non-proline residues

Number of end-residues (excl. Gly and Pro)

Number of glycine residues (shown as triangles)

Number of proline residues

Total number of residues

Tumber of proline residues

Fig 2

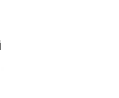



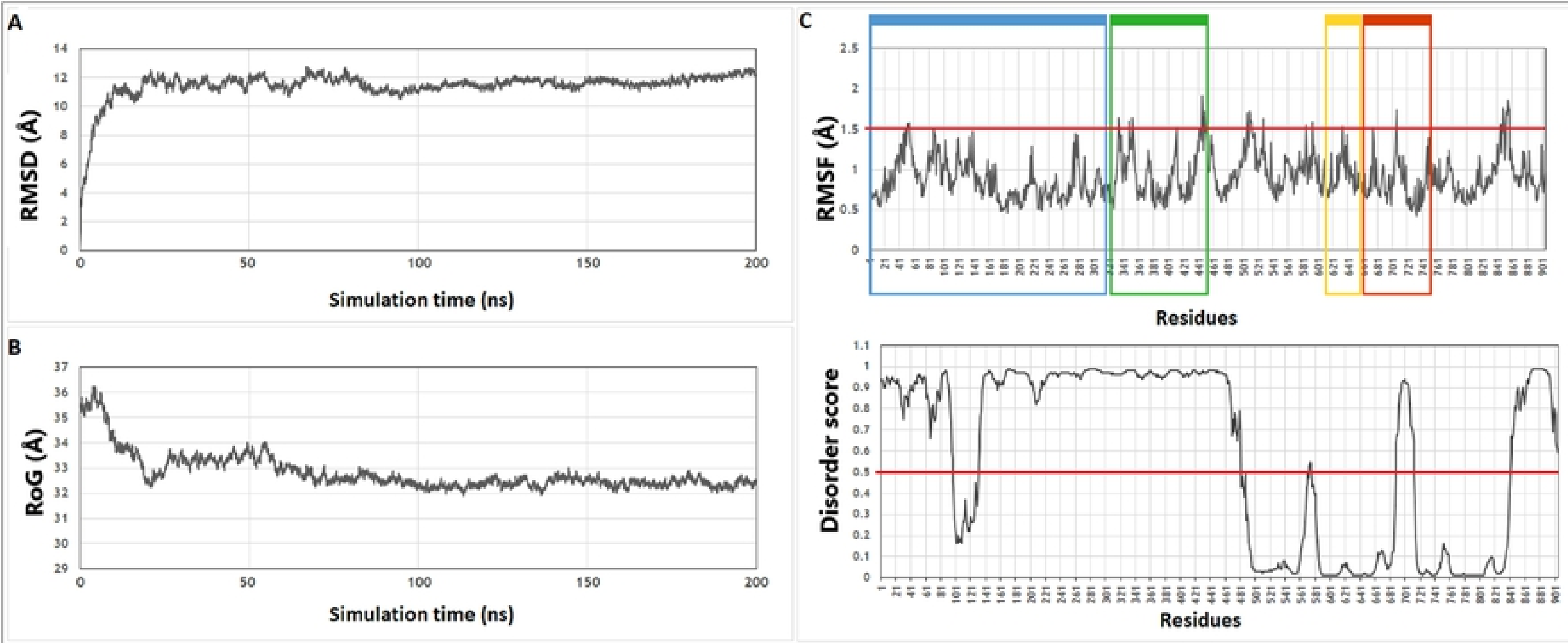

Fig 4 
A

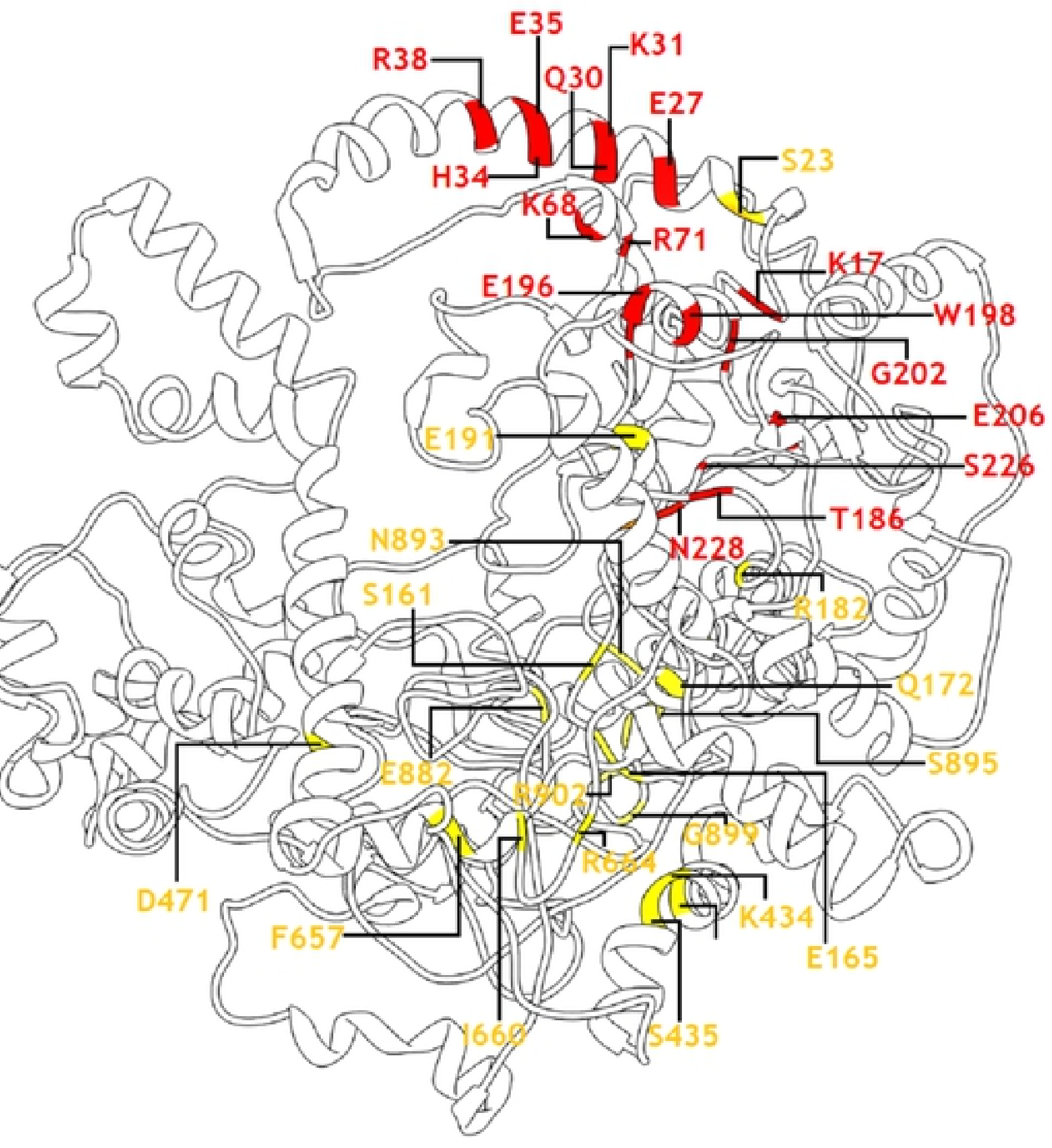

B

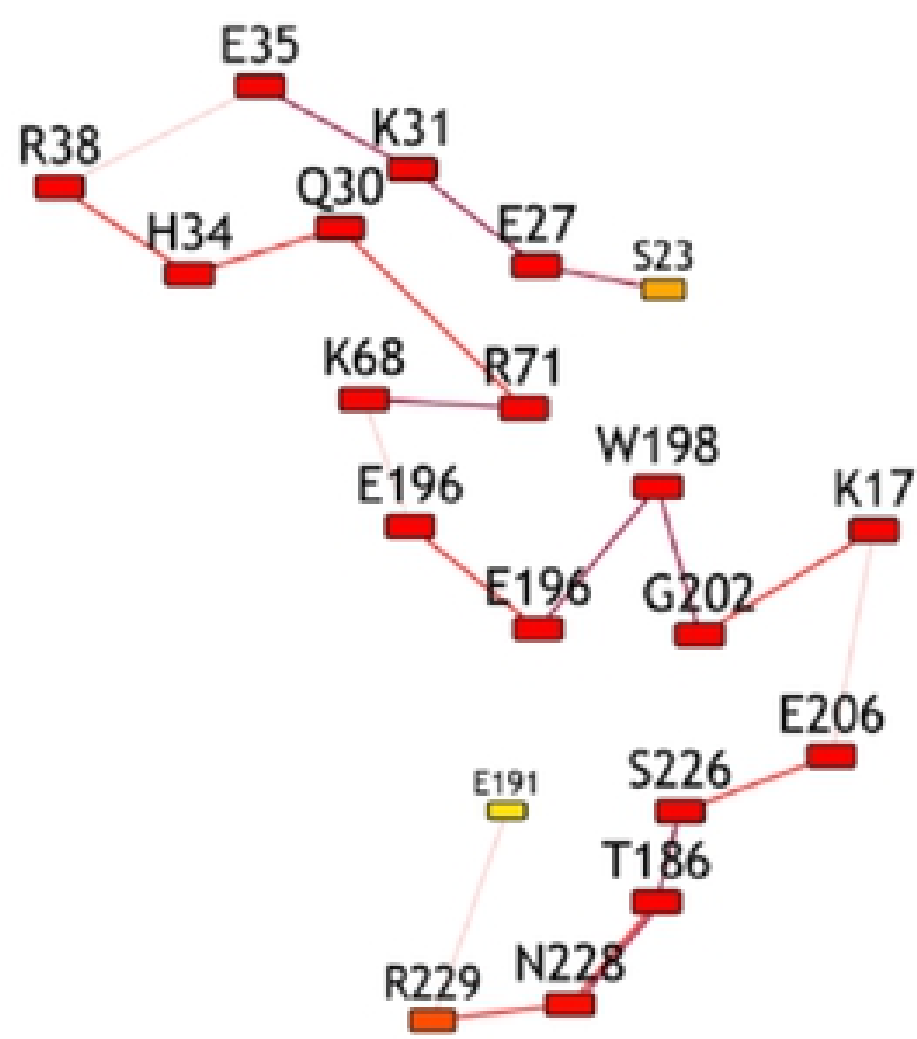

염

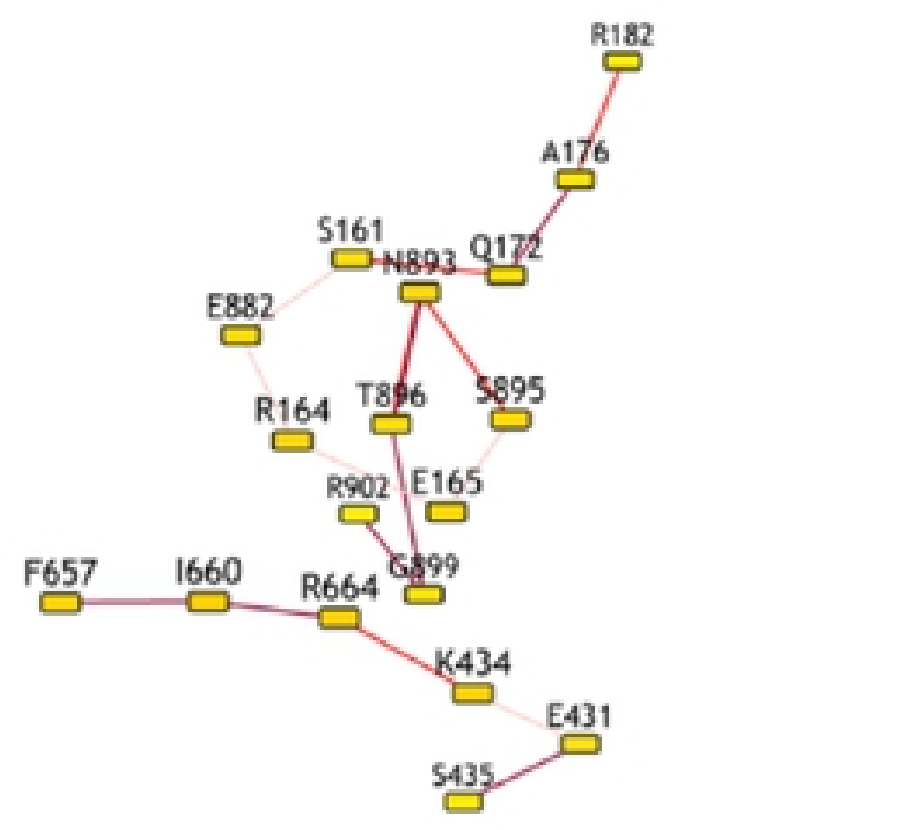

Fig 6 
Protein Classification

SANT/Myb-like DNA-binding domain-containing protein (domain architecture ID 10621698)

SANT/Myb-like DNA-binding domain-containing protein binds DNA and may function as a transcription factor

Graphical summary $\square$ zoom to residue level show extra options s

|

$4+4$

ste

Specific hit:

eiert superten

Superfanilies

$<$

List of domain hits

Name Accession Description [+] Myb_DNA-bind_6 pfam13921

Myb-like DNA-binding domain; This family contains the DNA binding domains from Myb proteins,

Interval

$621-677$

E-value

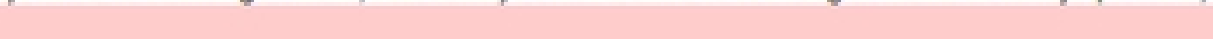

-

S 2 Fig 